Federal Reserve Bank of Dallas

Globalization and Monetary Policy Institute

Working Paper No. 180

http:// www.dallasfed.org/ assets/ documents/ institute/ wpapers/2014/ 0180.pdf

\title{
Theory and Practice of GVAR Modeling *
}

\author{
Alexander Chudik \\ Federal Reserve Bank of D allas \\ M. Hashem Pesaran \\ University of Southern California and Trinity College
}

May 2014

\begin{abstract}
The Global Vector Autoregressive (GVAR) approach has proven to be a very useful approach to analyze interactions in the global macroeconomy and other data networks where both the cross-section and the time dimensions are large. This paper surveys the latest developments in the GVAR modeling, examining both the theoretical foundations of the approach and its numerous empirical applications. We provide a synthesis of existing literature and highlight areas for future research.
\end{abstract}

JEL codes: C32, E17

\footnotetext{
* Alexander Chudik, Federal Reserve Bank of Dallas, Research Department, 2200 N. Pearl Street, Dallas, TX 75201. 214-922-5769. alexander.chudik@dal.frb.org. M. Hashem Pesaran, Department of Economics, University of Southern California, 3620 South Vermont Avenue, Kaprielian Hall 300, Los Angeles, CA 90089-0253. pesaran@usc.edu. The views in this paper are those of the authors and do not necessarily reflect the views of the Federal Reserve Bank of Dallas or the Federal Reserve System.
} 


\section{Introduction}

Individual economies in the global economy are interlinked through many different channels in a complex way. These include sharing scarce resources (such as oil and other commodities), political and technological developments, cross-border trade in financial assets as well as trade in goods and services, labor and capital movement across countries. Even after allowing for such effects, there might still be residual interdependences due to unobserved interactions and spillover effects not taken properly into account by using the common channels of interactions. Taking account of these channels of interactions pose a major challenge to modelling the global economy and conducting policy simulations and scenario analysis.

The Global VAR (GVAR) approach, originally proposed in Pesaran et al. (2004), provides a relatively simple yet effective way of modelling complex high-dimensional systems such as the global economy. Although GVAR is not the first large global macroeconomic model of the world economy, its methodological contributions lay in dealing with the curse of dimensionality (i.e. the proliferation of parameters as the dimension of the model grows) in a theoretically coherent and statistically consistent manner. Other existing large models are often incomplete and do not present a closed system, which is required for scenario analysis, see Granger and Jeon (2007) for a recent overview of global models.

The GVAR approach was originally developed in the aftermath of the 1997 Asian financial crisis to quantify the effects of macroeconomic developments on the losses of major financial institutions. It was clear then that all major banks are highly exposed to systemic risk from adverse global or regional shocks, but quantifying these effects required a coherent global macroeconomic model. The GVAR approach provides a useful and practical way of building such a model, and, although developed originally as a tool for credit risk analysis, it soon became apparent that it has numerous

other applications. This paper surveys the GVAR approach, focusing on theoretical foundations of the approach as well as its empirical applications.

The GVAR approach can be briefly summarized as a two-step approach. In the first step, small scale country-specific models are estimated conditional on the rest of the world. These models feature domestic variables and (weighted) cross section averages of foreign variables, which are also commonly referred to as 'star variables' and are treated as weakly exogenous (or long-run forcing). 
In the second step, individual country VARX* models are stacked and solved simultaneously as one large global VAR model. The solution can be used for shock scenario analysis and forecasting as is usually done with standard low-dimensional VAR models.

The simplicity and usefulness of this approach has proven to be quite attractive and there are numerous applications of the GVAR approach. Individual units need not necessarily be countries, but could be regions, industries, goods categories, banks, municipalities, or sectors of a given economy, just to mention a few notable examples. Mixed cross section GVAR models, for instance linking country data with firm-level data, have also been considered in the literature. The GVAR approach is conceptually simple, although it requires some programming skills since it handles large data sets, and it is not yet incorporated in any of the mainstream econometric software packages. Fortunately, an open source toolbox developed by Smith and Galesi (2014) together with a global macroeconomic dataset can be obtained from the web at: https://sites.google.com/site/gvarmodelling/. This toolbox has greatly facilitated empirical research using the GVAR methodology.

We start our survey with methodological considerations, starting with large linear dynamic systems. We suppose that the large set of variables under consideration are all endogenously determined in a factor augmented high-dimensional VAR model. This model allows for a very general pattern of interlinkages among variables, but, as it is well known, cannot be estimated consistently due to the curse of dimensionality when the cross section dimension $(N)$ is large. GVAR is one of the three common solutions to the curse of dimensionality, alongside popular factorbased modelling approaches and Bayesian VARs. We introduce the GVAR approach as originally proposed by Pesaran et al. (2004) and then review conditions (on the underlying unobserved highdimensional VAR data generating process) that justify the individual equations estimated in the GVAR approach when $N$ and $T$ (the time dimension) are large, and of the same order of magnitude. Next, we survey the impulse response analysis, forecasting, analysis of long-run and specification tests in the GVAR approach. Last but not least, we review empirical GVAR applications. We separate forecasting from non-forecasting applications, and we divide the latter group of empirical papers into global applications (featuring countries) and the remaining sectoral/other applications, where cross section units represent sectors, industries or regions within a given economy.

The remainder of the paper is organized as follows. Section 2 introduces high-dimensional factor- 
augmented VAR model and outlines the curse of dimensionality in modelling large linear dynamic systems. Section 3 presents the GVAR solution to this problem. Section 4 reviews methodological foundations for the individual equations estimated in the GVAR approach. Section 5 reviews impulse response analysis with GVARs, Section 6 discusses forecasting with GVARs, Section 7 considers analysis of long-run, and Section 8 discusses specification tests for the individual equations estimated in the GVAR approach. Section 9 surveys the empirical applications of the approach and Section 10 presents some concluding remarks.

A brief word on notations: $\|\mathbf{A}\|_{1} \equiv \max _{1 \leq j \leq n} \sum_{i=1}^{n}\left|a_{i j}\right|$ and $\|\mathbf{A}\|_{\infty} \equiv \max _{1 \leq i \leq n} \sum_{j=1}^{n}\left|a_{i j}\right|$ denote the maximum absolute column and row sum matrix norms of $\mathbf{A} \in \mathbb{M}^{n \times n}$, respectively, where $\mathbb{M}^{n \times n}$ is the space of real-valued $n \times n$ matrices. $\|\mathbf{A}\|=\sqrt{\varrho\left(\mathbf{A}^{\prime} \mathbf{A}\right)}$ is the spectral norm of $\mathbf{A}$, $\varrho(\mathbf{A})=\left|\lambda_{\max }(\mathbf{A})\right|$ is the spectral radius of $\mathbf{A}$, and $\lambda_{\max }(\mathbf{A})$ is the largest eigenvalue of $\mathbf{A} .^{1}$ Matrices are represented by bold upper case letters and vectors are represented by bold lower case letters. All vectors are column vectors. Most variables, vectors and matrices below depend on $N$, but we do not show this dependence explicitly.

\section{Large scale VAR reduced form representation of data}

Consider a panel of $N$ cross section units, each featuring $k_{i}$ variables observed during the time periods $t=1,2, \ldots, T$. Let $\mathbf{x}_{i t}$ denote a $k_{i} \times 1$ vector of variables specific to cross-section unit $i$ in time period $t$, and let $\mathbf{x}_{t}=\left(\mathbf{x}_{1 t}^{\prime}, \mathbf{x}_{1 t}^{\prime}, \ldots, \mathbf{x}_{N t}^{\prime}\right)^{\prime}$ denote a $k \times 1$ vector of all variables in the panel, where $k=\sum_{i=1}^{N} k_{i}$. Suppose that $\mathbf{x}_{t}$ is generated according to the following factor augmented $\operatorname{VAR}(p)$ model,

$$
\boldsymbol{\Theta}(L, p) \mathbf{x}_{t}=\boldsymbol{\Gamma}_{f}\left(L, s_{f}\right) \mathbf{f}_{t}+\boldsymbol{\Gamma}_{\omega}\left(L, s_{\omega}\right) \boldsymbol{\omega}_{t}+\mathbf{u}_{t}
$$

where $L$ is the time lag operator, $\boldsymbol{\Theta}(L, p)=\mathbf{I}_{k}-\sum_{\ell=1}^{p} \boldsymbol{\Theta}_{\ell} L^{\ell}$ is a matrix lag polynomial in $L, \boldsymbol{\Theta}_{\ell}$ for $\ell=1,2, \ldots, p$ are $k \times k$ matrices of unknown coefficients, $\boldsymbol{\Gamma}_{a}(L)=\sum_{\ell=1}^{s_{a}} \boldsymbol{\Gamma}_{a \ell} L^{\ell}$, for $a=f, \omega, \boldsymbol{\Gamma}_{a \ell}$ for $\ell=1,2, \ldots, s$ and $a=f, \omega$ are $k \times m_{a}$ matrices of factor loadings, $\mathbf{f}_{t}$ is the $m_{f} \times 1$ vector of unobserved common factors, $\boldsymbol{\omega}_{t}$ is the $m_{\omega} \times 1$ vector of observed common effects, and $\mathbf{u}_{t}$ is a $k \times 1$ vector of reduced form errors with zero means, and the $k \times k$ covariance matrix, $\boldsymbol{\Sigma}_{u}=E\left(\mathbf{u}_{t} \mathbf{u}_{t}^{\prime}\right)$. We abstract

\footnotetext{
${ }^{1}$ Note that if $\mathbf{x}$ is a vector, then $\|\mathbf{x}\|=\sqrt{\varrho\left(\mathbf{x}^{\prime} \mathbf{x}\right)}=\sqrt{\mathbf{x}^{\prime} \mathbf{x}}$ corresponds to the Euclidean length of vector $\mathbf{x}$.
} 
from deterministic terms for clarity of exposition, but such terms can be easily incorporated in the analysis. GVAR allows for very general forms of interdependencies across individual variables within a given unit and/or across units, since lags of all $k$ variables enter individual equations, and the reduced form errors are allowed to be cross-sectionaly dependent. GVAR can also be extended to allow for time-varying parameters, non-linearities, or threshold effects. But such extensions are not considered in this review. ${ }^{2}$

VAR models provide a rather general description of linear dynamic systems, but their number of unknown parameters to be estimated grows at a quadratic rate in the dimension of the model, $k$. We are interested in applications where the cross section dimension, $N$, as well as the time series dimension, $T$, can be both relatively large, while $k_{i}$, for $i=1,2, \ldots, N$, are uniformly small, so that $k=O(N)$. A prominent example arises in the case of global macroeconomic modelling, where the number of cross section units is relatively large but the number of variables considered within each cross section unit (such as real output, inflation, stock prices and interest rates) is small. Understanding the transmission of shocks across economies (space) and time is a key question in this example. Clearly in such settings unrestricted VAR models cannot be estimated due to the proliferation of unknown parameters (often referred to as the curse of dimensionality). The main problem is how to impose a plethora restrictions on the model (1) so that the parameters can be consistently estimated as $N, T \stackrel{j}{\rightarrow} \infty$, while still allowing for a general pattern of interdependencies between the individual variables.

There are three main approaches developed for modeling data-sets with a large number of variables: models that utilize common factors (e.g. small-scale factor-augmented VARs), Bayesian VARs and the global VARs. Factor models can be interpreted as data shrinkage procedures, where a large set of variables is shrunk into a small set of factors. ${ }^{3,4}$ Estimated factors can be used together with the vector of domestic variables to form a small scale model, as in factor-augmented VAR

\footnotetext{
${ }^{2}$ Extensions of the linear setting to allow for non-linearities could also be considered, but most of the GVAR papers in the literature are confined to a linear framework. Few exceptions include Binder and Gross (2013) who develop a Regime-Switching GVAR model and GVAR papers that consider time-varying weights.

${ }^{3}$ Dynamic factor models were introduced by Geweke (1977) and Sargent and Sims (1977), which have more recently been generalized to allow for weak cross-sectional dependence by Forni and Lippi (2001), Forni et al. (2000) and Forni et al. (2004).

${ }^{4}$ Stock and Watson (1999), Stock and Watson (2002), Giannone, Reichlin, and Sala (2005) conclude that only few, perhaps two, factors explain much of the predictable variations, while Bai and $\mathrm{Ng}$ (2007) estimate four factors and Stock and Watson (2005) estimate as many as seven factors.
} 
models (Bernanke, Bovian, and Eliasz (2005) and Stock and Watson (2005)). Bayesian VARs, on the other hand, explicitly shrink the parameter space by imposing tight priors on all or a subset of parameters. Large scale Bayesian VARs have been explored, among others, by Giacomini and White (2006), De Mol, Giannone, and Reichlin (2008), Carriero, Kapetanios, and Marcellino (2009), and Banbura, Giannone, and Reichlin (2010). Last but not least, the GVAR approach solves the dimensionality problem by decomposing the underlying large dimensional VARs into a smaller number of conditional models, which are linked together via cross sectional averages. The GVAR approach imposes an intuitive structure on cross-country interlinkages and no restrictions are imposed on the dynamics of the individual country sub-models. In the case where the number of lags is relatively large (compared to the time dimension of the panel) and/or the number of country specific variables is moderately large, it is possible to combine the GVAR structure with shrinkage estimation approaches in light of the usual bias-variance trade-offs. Bayesian estimation of country-specific sub-models that feature in the GVAR approach have been considered, for instance in Feldkircher et al. (2014).

\section{The GVAR solution to the curse of dimensionality}

The GVAR approach was originally proposed by Pesaran et al. (2004) (PSW) as a pragmatic approach to building a coherent global model of the world economy. We follow the exposition of PSW and introduce the GVAR approach initially without the inclusion of common variables.

At the core of the GVAR approach are small-scale country specific conditional models that can be estimated separately. These individual country models explain the domestic variables of the economy, collected in the $k_{i} \times 1$ vector $\mathbf{x}_{i t}$, and country-specific cross-section averages of foreign variables, collected in the $k^{*} \times 1$ vector

$$
\mathbf{x}_{i t}^{*}=\tilde{\mathbf{W}}_{i}^{\prime} \mathbf{x}_{t}
$$

for $i=1,2, \ldots, N$, where $\tilde{\mathbf{W}}_{i}$ is $k \times k^{*}$ matrix of country-specific weights typically constructed using data on bilateral foreign trade or capital flows. ${ }^{5}$ Both $k_{i}$ and $k^{*}$ are treated as small (typically 3 to

\footnotetext{
${ }^{5}$ It is straightforward to accommodate different number of star variables across countries $\left(k_{i}^{*}\right.$ instead of $\left.k^{*}\right)$, if desired.
} 
6). A larger number of domestic variables can be easily incorporated within the GVAR framework as well by using shrinkage methods applied to the country-specific submodels. $\mathbf{x}_{i t}$ is modeled as a VAR augmented by the vector of the 'star' variables $\mathbf{x}_{i t}^{*}$, and its lagged values,

$$
\mathbf{x}_{i t}=\sum_{\ell=1}^{p_{i}} \boldsymbol{\Phi}_{i \ell} \mathbf{x}_{i, t-\ell}+\boldsymbol{\Lambda}_{i 0} \mathbf{x}_{i t}^{*}+\sum_{\ell=1}^{q_{i}} \boldsymbol{\Lambda}_{i \ell} \mathbf{x}_{i, t-\ell}^{*}+\varepsilon_{i t}
$$

for $i=1,2, \ldots, N$, where $\boldsymbol{\Phi}_{i \ell}$, for $\ell=1,2, \ldots, p_{i}, \boldsymbol{\Lambda}_{i \ell}$, for $\ell=0,1,2, \ldots q_{i}$, are $k_{i} \times k_{i}$ and $k_{i} \times k^{*}$ matrices of unknown parameters, respectively, and $\varepsilon_{i t}$ are $k_{i} \times 1$ error vectors. We continue to abstract from the deterministic terms and observed common effects from the country-specific conditional VARX* models in (3).

Let $\mathbf{z}_{i t}=\left(\mathbf{x}_{i t}^{\prime}, \mathbf{x}_{i t}^{* \prime}\right)^{\prime}$ be $k_{i}+k^{*}$ dimensional vector of domestic and country-specific foreign variables included in the submodel of country $i$ and re-write (3) as

$$
\mathbf{A}_{i 0} \mathbf{z}_{i t}=\sum_{\ell=1}^{p} \mathbf{A}_{i \ell} \mathbf{z}_{i t-\ell}+\boldsymbol{\varepsilon}_{i t}
$$

where

$$
\mathbf{A}_{i 0}=\left(\mathbf{I}_{k_{i}},-\boldsymbol{\Lambda}_{i 0}\right), \mathbf{A}_{i \ell}=\left(\boldsymbol{\Phi}_{i \ell}, \boldsymbol{\Lambda}_{i \ell}\right) \text { for } \ell=1,2, \ldots, p
$$

$p=\max _{i}\left(p_{i}, q_{i}\right)$, and define $\boldsymbol{\Phi}_{i \ell}=\mathbf{0}$ for $\ell>p_{i}$, and similarly $\boldsymbol{\Lambda}_{i \ell}=0$ for $\ell>q_{i}$. Individual country-models in (4) can be equivalently written in the form of error-correction representation,

$$
\Delta \mathbf{x}_{i t}=\boldsymbol{\Lambda}_{i 0} \Delta \mathbf{x}_{i t}^{*}-\boldsymbol{\Pi}_{i} \mathbf{z}_{i, t-1}+\sum_{\ell=1}^{p} \mathbf{H}_{i \ell} \Delta \mathbf{z}_{i, t-1}+\boldsymbol{\varepsilon}_{i t},
$$

where $\Delta=1-L$ is the usual first difference operator, and

$$
\boldsymbol{\Pi}_{i}=\mathbf{A}_{i 0}-\sum_{\ell=1}^{p} \mathbf{A}_{i \ell}, \text { and } \mathbf{H}_{i \ell}=-\left(\mathbf{A}_{i, \ell+1}+\mathbf{A}_{i, \ell+2}+\ldots+\mathbf{A}_{i, \ell+p}\right)
$$

Star variables $\mathbf{x}_{i t}^{*}$ are treated as weakly exogenous for the purpose of estimating (5). Econometric theory for estimating $\operatorname{VARX}^{*}\left(p_{i}, q_{i}\right)$ models with weakly exogenous $I(1)$ regressors have been developed by Harbo et al. (1998) and Pesaran et al. (2000). The assumption of weak exogeneity can be easily tested as outlined in Section 7.1 of PSW, and typically is not rejected, when the 
economy under consideration is small relative to the rest of the world and the weights used in the construction of the star variables are granular.

It is clear from (5) that country specific models allow for cointegration both within domestic variables as well as between domestic and foreign (star) variables. In particular, assuming $\mathbf{z}_{i t}$ is $I(1)$, the rank of $\boldsymbol{\Pi}_{i}$, denoted as $r_{i}=\operatorname{rank}\left(\boldsymbol{\Pi}_{i}\right) \leq k_{i}$, specifies the number of cointegrating relationships that exist among the domestic and country-specific foreign variables in $\mathbf{z}_{i t}$; and $\mathbf{\Pi}_{i}$ can be decomposed as

$$
\boldsymbol{\Pi}_{i}=\boldsymbol{\alpha}_{i} \boldsymbol{\beta}_{i}^{\prime}
$$

where $\boldsymbol{\alpha}_{i}$ is $k_{i} \times r_{i}$ full column rank loading matrix and $\boldsymbol{\beta}_{i}$ is the $\left(k_{i}+k^{*}\right) \times r_{i}$ full column rank matrix of cointegrating vectors. It is well known that this decomposition is not unique and the identification of long-run relationships requires theory-based restrictions (see Section 7).

Country models in (3) resemble the small open economy (SOE) macroeconomic models in the literature, where domestic variables are modelled conditional on the rest of the world. The difference between the SOE framework and the country-specific VARX* models is in the treatment of star variables: SOE typically treats them as strictly exogenous, whereas in the GVAR approach they are typically treated as weakly exogenous. This difference, although important, is however not where the action comes in alleviating the curse of dimensionality. ${ }^{6}$ The main action comes from the data shrinkage given by (2). Under what conditions it is valid to specify (3), where the rest-of-the-world economies are aggregated as given by (2) and treated as weakly exogenous is reviewed in Section 4. The estimation of country models in (3), which allows for cointegration within and across countries (via the star variables), is the first step of the GVAR approach.

The second step of the GVAR approach consists of stacking estimated country models into one large global VAR model. Using the $\left(k_{i}+k^{*}\right) \times k$ dimensional 'link' matrices $\mathbf{W}_{i}=\left(\mathbf{E}_{i}^{\prime}, \tilde{\mathbf{W}}_{i}^{\prime}\right)$, where $\mathbf{E}_{i}$ is $k \times k_{i}$ dimensional selection matrix that select $\mathbf{x}_{i t}$, namely $\mathbf{x}_{i t}=\mathbf{E}_{i}^{\prime} \mathbf{x}_{t}$, and $\tilde{\mathbf{W}}_{i}^{\prime}$ is the weight matrix introduced in (2) to define country-specific foreign star variables, we have

$$
\mathbf{z}_{i t}=\left(\mathbf{x}_{i t}^{\prime}, \mathbf{x}_{i t}^{* \prime}\right)^{\prime}=\mathbf{W}_{i} \mathbf{x}_{t}
$$

\footnotetext{
${ }^{6}$ Note that since $k_{i}$ and $k^{*}$ are considered small it is feasible to estimate VAR model $\left(\mathbf{x}_{i t}^{\prime}, \mathbf{x}_{i t}^{* \prime}\right)^{\prime}$ treating domestic and foreign star variables as endogenous.
} 
Using (6) in (4) we obtain

$$
\mathbf{A}_{i 0} \mathbf{W}_{i} \mathbf{x}_{t}=\sum_{\ell=1}^{p} \mathbf{A}_{i \ell} \mathbf{W}_{i} \mathbf{x}_{t-\ell}+\varepsilon_{i t}
$$

and stacking these models for $i=1,2, \ldots, N$, we obtain

$$
\mathbf{G}_{0} \mathbf{x}_{t}=\sum_{\ell=1}^{p} \mathbf{G}_{\ell} \mathbf{x}_{t-\ell}+\varepsilon_{t}
$$

where $\varepsilon_{t}=\left(\varepsilon_{1 t}^{\prime}, \varepsilon_{2 t}^{\prime}, \ldots, \varepsilon_{N t}^{\prime}\right)^{\prime}$, and

$$
\mathbf{G}_{\ell}=\left(\begin{array}{c}
\mathbf{A}_{1, \ell} \mathbf{W}_{1} \\
\mathbf{A}_{2, \ell} \mathbf{W}_{2} \\
\vdots \\
\mathbf{A}_{N, \ell} \mathbf{W}_{N}
\end{array}\right)
$$

If matrix $\mathbf{G}_{0}$ is invertible, then by multiplying (8) by $\mathbf{G}_{0}^{-1}$ from the left we obtain the GVAR model

$$
\mathbf{x}_{t}=\sum_{\ell=1}^{p} \mathbf{F}_{\ell} \mathbf{x}_{t-\ell}+\mathbf{G}_{0}^{-1} \varepsilon_{t}
$$

where $\mathbf{F}_{\ell}=\mathbf{G}_{0}^{-1} \mathbf{G}_{\ell}$ for $\ell=1,2, \ldots, p$. PSW established that the overall number of cointegrating relationships in the GVAR model (9) cannot exceed the total number of long-run relations $\sum_{i=1}^{N} r_{i}$ that exist in country-specific models.

\subsection{Rank of $\mathrm{G}_{0}$}

The GVAR model (9) is derived under the assumption that the contemporaneous coefficient matrix, $\mathbf{G}_{0}$, is full rank. To clarify the role of this assumption and to illustrate the consequences of possible rank deficiency of $\mathbf{G}_{0}$, consider the following illustrative GVAR model,

$$
\mathbf{x}_{i t}=\boldsymbol{\Lambda}_{i 0} \mathbf{x}_{i t}^{*}+\varepsilon_{i t}, \text { for } i=1,2, \ldots, N \text {, }
$$

where we abstract from lags of $\left(\mathbf{x}_{i t}^{\prime}, \mathbf{x}_{i t}^{* \prime}\right)^{\prime}$. Let $\boldsymbol{\Lambda}_{0}$ be the $k \times k$ block diagonal matrix defined by $\boldsymbol{\Lambda}_{0}=\operatorname{diag}\left(\boldsymbol{\Lambda}_{i 0}\right)$, and let $\tilde{\mathbf{W}}^{\prime}=\left(\tilde{\mathbf{W}}_{1}, \tilde{\mathbf{W}}_{2}, \ldots, \tilde{\mathbf{W}}_{N}\right)$. Write $(10)$ as

$$
\mathbf{x}_{t}=\boldsymbol{\Lambda}_{0} \tilde{\mathbf{W}} \mathbf{x}_{t}+\varepsilon_{t}
$$




$$
\mathbf{G}_{0} \mathbf{x}_{t}=\varepsilon_{t}
$$

where $\mathbf{G}_{0}=\mathbf{I}_{N}-\boldsymbol{\Lambda}_{0} \tilde{\mathbf{W}}$. Suppose that $\mathbf{G}_{0}$ is rank deficient, namely $\operatorname{rank}\left(\mathbf{G}_{0}\right)=k-m$, for some $m>0$. Then the solution of (11) exists only if $\varepsilon_{t}$ lies in the range of $\mathbf{G}_{0}$, denoted as $\operatorname{Col}\left(\mathbf{G}_{0}\right)$. Assuming this is the case, system (11) does not uniquely determine $\mathbf{x}_{t}$, and the set of all possible solutions can be characterized as

$$
\mathbf{x}_{t}=\widetilde{\Gamma}_{t}+\mathbf{G}_{0}^{+} \varepsilon_{t}
$$

where $\widetilde{\mathbf{f}}_{t}$ is any $m \times 1$ arbitrary stochastic process, $\boldsymbol{\Gamma}$ is a $k \times m$ matrix which is a basis of the null space of $\mathbf{G}_{0}$, namely $\mathbf{G}_{0} \boldsymbol{\Gamma}=\mathbf{0}, \operatorname{rank}\left(\boldsymbol{\Gamma}^{\prime} \boldsymbol{\Gamma}\right)=m$, and $\mathbf{G}_{0}^{+}$is the Moore-Penrose pseudo-inverse of $\mathbf{G}_{0}$. To verify that (12) maps all possible solutions of (11), note that $\mathbf{G}_{0}^{+} \varepsilon_{t}$ is the particular solution of (11) and $\boldsymbol{\Gamma}^{\prime} \widetilde{\mathbf{f}}_{t}$ is a general solution of the homogenous counterpart of (11), namely the set of equations $\mathbf{G}_{0} \mathbf{x}_{t}=\mathbf{0}$. To prove the former, we have

$$
\mathbf{G}_{0} \mathbf{G}_{0}^{+} \varepsilon_{t}=\varepsilon_{t}
$$

since $\varepsilon_{t}$ lies in the range of $\mathbf{G}_{0}$ by assumption and $\mathbf{G}_{0} \mathbf{G}_{0}^{+}$is the orthogonal projector onto the range of $\mathbf{G}_{0}$. To prove the latter, we note that $\boldsymbol{\Gamma}$ is a basis of the null space of $\mathbf{G}_{0}$ and therefore $\mathbf{G}_{0} \boldsymbol{\Gamma} \mathbf{f}_{t}=\mathbf{0}$ for any $m \times 1$ arbitrary stochastic process $\widetilde{\mathbf{f}}_{t}$, and the set of solutions must be complete since the dimension of $\operatorname{Col}(\boldsymbol{\Gamma})$ is $m$.

Let $\mathbf{f}_{t}=\widetilde{\mathbf{f}}_{t}-E\left(\widetilde{\mathbf{f}}_{t} \mid \varepsilon_{t}\right)=\widetilde{\mathbf{f}}_{t}-\mathbf{D}^{\prime} \varepsilon_{t}$. Then (12) can also be written as an approximate factor model, namely

$$
\mathbf{x}_{t}=\boldsymbol{\Gamma} \mathbf{f}_{t}+\mathbf{R} \varepsilon_{t}
$$

where $\mathbf{f}_{t}$ is uncorrelated with $\varepsilon_{t}$ by construction, and

$$
\mathbf{R}=\mathbf{\Gamma} \mathbf{M}^{\prime}+\mathbf{G}_{0}^{+}
$$

Without any loss of generality, it is standard convention to use the normalization $\operatorname{Var}\left(\mathbf{f}_{t}\right)=\mathbf{I}_{m}$, and to set the first non-zero element in each of the $m$ column vectors of $\boldsymbol{\Gamma}$ to be positive. These normalization conditions ensure that $\boldsymbol{\Gamma}$ is unique, in which case $\mathbf{R}$ is unique up to the rotation 
matrix, M. Note also that all of the findings above hold for any $N$.

Therefore, the full rank condition, $\operatorname{rank}\left(\mathbf{G}_{0}\right)=k$, is necessary and sufficient for $\mathbf{x}_{t}$, given by (10), to be uniquely determined. If $\mathbf{G}_{0}$ was known and $m>0$, then the GVAR model (10) would need to be augmented by $m$ equations that determine the $m$ cross section averages $\Gamma^{\prime} \mathbf{x}_{t}$ in order for $\mathbf{x}_{t}$ to be uniquely determined. Note that in practice $\mathbf{G}_{0}$ is not known, since $\boldsymbol{\Lambda}_{0}$ is not known, and needs to be estimated.

We provide further clarifications on the rank of $\mathbf{G}_{0}$ in Section 6 , where we review conditions under which the individual equations estimated in the GVAR approach can lead to a singular $\mathbf{G}_{0}$ or to the case when $\operatorname{det}\left(\mathbf{G}_{0}\right) \rightarrow 0$ as $N \rightarrow \infty$.

\subsection{Introducing common variables}

When common variables are present in the country models $\left(m_{\omega}>0\right)$, either as observed common factors or as dominant variables as defined in Chudik and Pesaran (2013b), then the conditional country models need to be augmented by $\boldsymbol{\omega}_{t}$ and its lag values in addition to the country-specific vector of cross-section averages of the foreign variables, namely

$$
\mathbf{x}_{i t}=\sum_{\ell=1}^{p_{i}} \boldsymbol{\Phi}_{i \ell} \mathbf{x}_{i, t-\ell}+\boldsymbol{\Lambda}_{i 0} \mathbf{x}_{i t}^{*}+\sum_{\ell=1}^{q_{i}} \boldsymbol{\Lambda}_{i \ell} \mathbf{x}_{i, t-\ell}^{*}+\mathbf{D}_{i 0} \boldsymbol{\omega}_{t}+\sum_{\ell=1}^{s_{i}} \mathbf{D}_{i \ell} \boldsymbol{\omega}_{t-\ell}+\boldsymbol{\varepsilon}_{i t}
$$

Both types of variables (common variables $\boldsymbol{\omega}_{t}$ and cross section averages $\mathbf{x}_{i t}^{*}$ ) can be treated as weakly exogenous for the purpose of estimation. As noted above, the weak exogeneity assumption is testable. Note that not all of the coefficients $\left\{\mathbf{D}_{i \ell}\right\}$ associated with the common variables need be significant and in the case when they are not significant, they could be excluded for the sake of parsimony, if desired. ${ }^{7}$ The marginal model for the dominant variables can be estimated with or without the feedback effects from $\mathbf{x}_{t}$. In the latter case, we have the following marginal model,

$$
\boldsymbol{\omega}_{t}=\sum_{\ell=1}^{p_{\omega}} \boldsymbol{\Phi}_{\omega \ell} \boldsymbol{\omega}_{t-\ell}+\boldsymbol{\eta}_{\omega t}
$$

\footnotetext{
${ }^{7}$ Chudik and Smith (2013) find that contemporaneous US variables are significant in individual non-US country models in about a quarter of cases. Moreover, weak exogeneity of the US variables is not rejected by data.
} 
which can be equivalently written in the error-correction form as

$$
\Delta \boldsymbol{\omega}_{t}=-\boldsymbol{\alpha}_{\omega} \boldsymbol{\beta}_{\omega}^{\prime} \boldsymbol{\omega}_{t-1}+\sum_{j=1}^{p_{\omega}-1} \mathbf{H}_{\omega j} \Delta \boldsymbol{\omega}_{t-j}+\boldsymbol{\eta}_{\omega t}
$$

where $\boldsymbol{\alpha}_{\omega} \boldsymbol{\beta}_{\omega}^{\prime}=\sum_{\ell=1}^{p_{\omega}} \boldsymbol{\Phi}_{\omega \ell}, \mathbf{H}_{\omega j}=-\left(\boldsymbol{\Phi}_{\omega, \ell+1}+\boldsymbol{\Phi}_{\omega, \ell+2}+\ldots+\boldsymbol{\Phi}_{\omega, \ell+p_{\omega}}\right)$. In the case of $I$ (1) variables, representation (15) clearly allows for cointegration among the dominant variables. To allow for feedback effects from the variables in the GVAR model back to the dominant variables via crosssection averages, VAR model (14) can be augmented by lags of $\mathbf{x}_{\omega t}^{*}=\tilde{\mathbf{W}}_{\omega} \mathbf{x}_{t}$, where $\tilde{\mathbf{W}}_{\omega}$ is a $k^{*} \times k$ dimensional weight matrix defining $k^{*}$ global cross section averages,

$$
\boldsymbol{\omega}_{t}=\sum_{\ell=1}^{p_{\omega}} \boldsymbol{\Phi}_{\omega \ell} \boldsymbol{\omega}_{i, t-\ell}+\sum_{\ell=1}^{q_{\omega}} \boldsymbol{\Lambda}_{\omega \ell} \mathbf{x}_{i, t-\ell}^{*}+\boldsymbol{\eta}_{\omega t} .
$$

Assuming there is no cointegration among the common variables, $\boldsymbol{\omega}_{t}$, and the cross-section averages, $\mathbf{x}_{i, t-\ell}^{*},(16)$ can be written as

$$
\Delta \boldsymbol{\omega}_{t}=-\boldsymbol{\alpha}_{\omega} \boldsymbol{\beta}_{\omega}^{\prime} \boldsymbol{\omega}_{t-1}+\sum_{j=1}^{p_{\omega}-1} \mathbf{H}_{\omega j} \Delta \boldsymbol{\omega}_{t-j}+\sum_{j=1}^{q_{\omega}-1} \mathbf{B}_{\omega j} \Delta \mathbf{x}_{\omega, t-j}^{*}+\boldsymbol{\eta}_{\omega t}
$$

where $\mathbf{B}_{\omega \ell}=-\left(\boldsymbol{\Lambda}_{\omega, \ell+1}+\boldsymbol{\Lambda}_{\omega, \ell+2}+\ldots+\boldsymbol{\Lambda}_{\omega, \ell+p}\right)$, and consistently estimated by least squares. Different lag orders for the dominant variables $\left(p_{\omega}\right)$ and cross section averages $\left(q_{\omega}\right)$ could be considered. Note that contemporaneous values of star variables do not feature in (17). Similar equations to (16) for dominant variables are estimated in Holly, Hashem Pesaran, and Yamagata (2011) and in a stationary setting in Smith and Yamagata (2011).

Conditional models (13) and the marginal model (17) can be combined and solved as a complete global VAR model in the usual way. Specifically, let $\mathbf{y}_{t}=\left(\boldsymbol{\omega}_{t}^{\prime}, \mathbf{x}_{t}^{\prime}\right)^{\prime}$ be the $\left(k+m_{\omega}\right) \times 1$ vector of all observable variables. Using (6) in (13) and stacking country-specific conditional models (13) together with the model for common variables (16) yields

$$
\mathbf{G}_{y, 0} \mathbf{y}_{t}=\sum_{\ell=1}^{p} \mathbf{G}_{y, \ell} \mathbf{y}_{t-\ell}+\boldsymbol{\varepsilon}_{y t}
$$


where $\varepsilon_{y t}=\left(\varepsilon_{t}^{\prime}, \boldsymbol{\eta}_{\omega t}^{\prime}\right)^{\prime}$,

$$
\mathbf{G}_{y, 0}=\left(\begin{array}{cc}
\mathbf{I}_{m_{\omega}} & \mathbf{0}_{m_{\omega} \times k} \\
\mathbf{D}_{0} & \mathbf{G}_{0}
\end{array}\right), \mathbf{G}_{y, \ell}=\left(\begin{array}{cc}
\mathbf{\Phi}_{\omega \ell} & \boldsymbol{\Lambda}_{\omega \ell} \tilde{\mathbf{W}}_{\omega} \\
\mathbf{D}_{\ell} & \mathbf{G}_{\ell}
\end{array}\right), \text { for } \ell=1,2, \ldots, p,
$$

$\mathbf{D}_{\ell}=\left(\mathbf{D}_{1 \ell}^{\prime}, \mathbf{D}_{2 \ell}^{\prime}, \ldots, \mathbf{D}_{N \ell}^{\prime}\right)^{\prime}$ for $\ell=0,1, \ldots, p, p=\max _{i}\left\{p_{i}, q_{i}, s_{i}, p_{\omega}, q_{\omega}\right\}$, and we define $\mathbf{D}_{i \ell}=\mathbf{0}$ for $\ell>s_{i}, \boldsymbol{\Phi}_{\omega \ell}=\mathbf{0}$ for $\ell>p_{\omega}$, and $\boldsymbol{\Lambda}_{\omega \ell}=\mathbf{0}$ for $\ell>q_{\omega}$. Matrix $\mathbf{G}_{y, 0}$ is invertible if and only if $\mathbf{G}_{0}$ is invertible. Assuming $\mathbf{G}_{0}^{-1}$ exists, the inverse of $\mathbf{G}_{y, 0}$ is

$$
\mathbf{G}_{y, 0}^{-1}=\left(\begin{array}{cc}
\mathbf{I}_{m_{\omega}} & \mathbf{0}_{m_{\omega} \times k} \\
-\mathbf{G}_{0}^{-1} \mathbf{D}_{0} & \mathbf{G}_{0}^{-1}
\end{array}\right)
$$

which is a block lower triangular matrix, showing the causal nature of the common (dominant) variables, $\boldsymbol{\omega}_{t}$. Multiplying both sides of (18) by $\mathbf{G}_{y, 0}^{-1}$ we now obtain the following GVAR model for $\mathbf{y}_{t}$ :

$$
\mathbf{y}_{t}=\sum_{\ell=1}^{p} \mathbf{F}_{y, \ell} \mathbf{y}_{t-\ell}+\mathbf{G}_{y, 0}^{-1} \varepsilon_{y} t
$$

where $\mathbf{F}_{y, \ell}=\mathbf{G}_{y, 0}^{-1} \mathbf{G}_{y, \ell}$, for $\ell=1,2, \ldots, p$.

\section{Theoretical justification of the GVAR approach}

GVAR approach as proposed by PSW builds on separate estimation of country-specific VARX* models based on the assumption that foreign variables are weakly exogenous. However, PSW did not provide a theoretical justification and it was left to the future literature to derive conditions under which the weak exogeneity assumptions underlying the GVAR approach are sustained. An overview of the subsequent literature is now provided.

\subsection{Approximating a global factor model}

A first attempt at a theoretical justification of the GVAR approach was provided by Dées et al. (2007) (DdPS), who derived (3) as an approximation to a global factor model. Their starting point is the following canonical global factor model (abstracting again from deterministic terms 
and observed factors)

$$
\mathbf{x}_{i t}=\boldsymbol{\Gamma}_{i} \mathbf{f}_{t}+\boldsymbol{\xi}_{i t}, \text { for } i=1,2, \ldots, N
$$

For each $i, \boldsymbol{\Gamma}_{i}$ is a $k_{i} \times m$ matrix of factor loadings, assumed to be uniformly bounded $\left(\left\|\boldsymbol{\Gamma}_{i}\right\|<\right.$ $K<\infty)$, and $\boldsymbol{\xi}_{i t}$ is a $k_{i} \times 1$ vector of country-specific effects. Factors and the country effects are assumed to satisfy

$$
\begin{aligned}
\Delta \mathbf{f}_{t} & =\boldsymbol{\Lambda}_{f}(L) \boldsymbol{\eta}_{f t}, \boldsymbol{\eta}_{f t} \sim \operatorname{IID}\left(\mathbf{0}, \mathbf{I}_{m}\right), \\
\Delta \boldsymbol{\xi}_{i t} & =\boldsymbol{\Xi}_{i}(L) \mathbf{u}_{i t}, \mathbf{u}_{i t} \sim \operatorname{IID}\left(\mathbf{0}, \mathbf{I}_{k_{i}}\right), \text { for } i=1,2, \ldots, N,
\end{aligned}
$$

where $\boldsymbol{\Lambda}_{f}(L)=\sum_{\ell=0}^{\infty} \boldsymbol{\Lambda}_{f \ell} L^{\ell}, \boldsymbol{\Xi}_{i}(L)=\sum_{\ell=0}^{\infty} \boldsymbol{\Xi}_{i \ell} L^{\ell}$, and the coefficient matrices $\boldsymbol{\Lambda}_{f \ell}$ and $\boldsymbol{\Xi}_{i \ell}$, for $i=1,2, \ldots, N$, are uniformly absolute summable, which ensures the existence of $\operatorname{Var}\left(\Delta \mathbf{f}_{t}\right)$ and $\operatorname{Var}\left(\Delta \boldsymbol{\xi}_{i t}\right)$. In addition, $\left[\boldsymbol{\Xi}_{i}(L)\right]^{-1}$ is assumed to exist.

Under these assumptions, after first differencing (20) and using (22), DdPS obtain

$$
\left[\boldsymbol{\Xi}_{i}(L)\right]^{-1}(1-L)\left(\mathbf{x}_{i t}-\boldsymbol{\Gamma}_{i} \mathbf{f}_{t}\right)=\mathbf{u}_{i t}
$$

Using the approximation

$$
(1-L)\left[\boldsymbol{\Xi}_{i}(L)\right]^{-1} \approx \sum_{\ell=0}^{p_{i}} \boldsymbol{\Phi}_{i \ell} L^{\ell}=\boldsymbol{\Phi}_{i}\left(L, p_{i}\right)
$$

DdPS further obtain the following approximate $\operatorname{VAR}\left(p_{i}\right)$ model with factors

$$
\boldsymbol{\Phi}_{i}\left(L, p_{i}\right) \mathbf{x}_{i t} \approx \boldsymbol{\Phi}_{i}\left(L, p_{i}\right) \boldsymbol{\Gamma}_{i} \mathbf{f}_{t}+\mathbf{u}_{i t}
$$

for $i=1,2, \ldots, N$, which is a special case of (1). Model (23) is more restrictive than (1) because lags of other units do not feature in (23), and the errors, $\mathbf{u}_{i t}$, are assumed to be cross sectionally independently distributed.

Unobserved common factors in (23) can be estimated by linear combinations of cross section averages of observable variables, $\mathbf{x}_{i t}$. As before, let $\tilde{\mathbf{W}}_{i}$ be the $k \times k^{*}$ matrix of country-specific 
weights and assume that it satisfies the usual granularity conditions

$$
\begin{aligned}
&\left\|\tilde{\mathbf{W}}_{i}\right\|<K N^{-\frac{1}{2}}, \text { for all } i \\
& \frac{\left\|\tilde{\mathbf{W}}_{i j}\right\|}{\left\|\tilde{\mathbf{W}}_{i}\right\|}<K N^{-\frac{1}{2}}, \text { for all } i, j,
\end{aligned}
$$

where $\tilde{\mathbf{W}}_{i j}$ are the blocks in the partitioned form of $\tilde{\mathbf{W}}_{i}=\left(\tilde{\mathbf{W}}_{i 1}^{\prime}, \tilde{\mathbf{W}}_{i 2}^{\prime}, \ldots, \tilde{\mathbf{W}}_{i N}^{\prime}\right)^{\prime}$, and the constant $K<\infty$ does not depend on $i, j$ or $N$. Taking cross section averages of $\mathbf{x}_{i t}$ given by (20) yields

$$
\mathbf{x}_{i t}^{*}=\tilde{\mathbf{W}}_{i}^{\prime} \mathbf{x}_{t}=\Gamma_{i}^{*} \mathbf{f}_{t}+\boldsymbol{\xi}_{i t}^{*}
$$

where $\left\|\boldsymbol{\Gamma}_{i}^{*}\right\|=\left\|\tilde{\mathbf{W}}_{i}^{\prime} \boldsymbol{\Gamma}\right\| \leq\left\|\tilde{\mathbf{W}}_{i}^{\prime}\right\|\|\boldsymbol{\Gamma}\|<K, \boldsymbol{\Gamma}=\left(\boldsymbol{\Gamma}_{1}^{\prime}, \boldsymbol{\Gamma}_{2}^{\prime}, \ldots, \boldsymbol{\Gamma}_{N}^{\prime}\right)^{\prime}$, and $\boldsymbol{\xi}_{i t}^{*}$ satisfies

$$
\Delta \boldsymbol{\xi}_{i t}^{*}=\sum_{j=0}^{N} \tilde{\mathbf{W}}_{i j}^{\prime} \Delta \boldsymbol{\xi}_{i t}=\sum_{j=0}^{N} \tilde{\mathbf{W}}_{i j}^{\prime} \boldsymbol{\Xi}_{i}(L) \mathbf{u}_{i t}
$$

Assuming that $\Delta \boldsymbol{\xi}_{i t}, i=1,2, \ldots, N$, are covariance stationary and weakly cross sectionally dependent, DdPS show that for each $t, \Delta \boldsymbol{\xi}_{i t}^{*} \stackrel{q . m .}{\rightarrow} \mathbf{0}$ as $N \rightarrow \infty$, which implies $\boldsymbol{\xi}_{i t}^{*} \stackrel{q . m .}{\rightarrow} \boldsymbol{\xi}_{i}^{*}$. It now follows that under the additional condition that $\boldsymbol{\Gamma}_{i}^{*}$ has a full column rank,

$$
\mathbf{f}_{t} \stackrel{q . m .}{\rightarrow}\left(\boldsymbol{\Gamma}_{i}^{* \prime} \boldsymbol{\Gamma}_{i}^{*}\right)^{-1} \boldsymbol{\Gamma}_{i}^{*}\left(\mathbf{x}_{i t}^{*}-\boldsymbol{\xi}_{i}^{*}\right)
$$

as $N \rightarrow \infty$, which justifies using $\left(1, \mathbf{x}_{i t}^{* \prime}\right)^{\prime}$ as proxies for the unobserved common factors. Thus, for $N$ sufficiently large, DdPS obtain the following country-specific VAR models augmented with $\mathbf{x}_{i t}^{*}$,

$$
\boldsymbol{\Phi}_{i}\left(L, p_{i}\right)\left(\mathbf{x}_{i t}-\widetilde{\boldsymbol{\delta}}_{i}-\widetilde{\boldsymbol{\Gamma}}_{i} \mathbf{x}_{i t}^{*}\right) \approx \mathbf{u}_{i t},
$$

where $\widetilde{\boldsymbol{\delta}}_{i}$ and $\widetilde{\boldsymbol{\Gamma}}_{i}$ are given in terms of $\boldsymbol{\xi}_{i}^{*}$ and $\boldsymbol{\Gamma}_{i}^{*}$. (26) motivates the use of VARX* conditional country models in (3) as an approximation to a global factor model.

Note that the weights $\left\{\tilde{\mathbf{W}}_{i}\right\}_{i=1}^{N}$ used in the construction of cross sectional averages only need to satisfy the granularity conditions (24) and (25), and for large $N$ asymptotics one might as well use equal weights, namely replace all cross sectional averages by simple averages. For the theory 
to work, it is only needed that $\Delta \boldsymbol{\xi}_{i t}^{*} \stackrel{q . m .}{\rightarrow} \mathbf{0}$ at a sufficiently fast rate as $N \rightarrow \infty$. For example, the weights could also be time-varying without any major consequences so long as the granularity conditions are met in each period. In practice, where the number of countries $(N)$ is moderate and spill over effects could also be of importance, it is advisable to use trade weights that also capture cultural and political interlinkages across countries. ${ }^{8}$ Trade weights can also be used to allow for time variations in the weights used when constructing the star variables. This is particularly important in cases where there are important shifts in the trade weights, as has occurred in the case of China and its trading partners. Allowing for such time variations is also important in analyzing the way shocks transmit across the globe. We review some of the empirical applications of the GVAR that employ time-varying weights.

The analysis of DdPS has been further extended by Chudik and Pesaran (2011) and Chudik and Pesaran (2013b) to allow for joint asymptotics (i.e. as $N$ and $T \rightarrow \infty$, jointly), and weak cross sectional dependence in the errors in the case of stationary variables. Further generalization of the theoretical results to allow for unit root processes are not yet available. ${ }^{9}$

\subsection{Approximating factor augmented stationary high dimensional VARs}

Chudik and Pesaran (2011) (CP) consider the conditions on the unknown parameters of the VAR model (1) that would deliver individual country models (3) when $N$ is large. CP consider the following factor augmented high dimensional VAR model (1),

$$
\left(\mathbf{x}_{t}-\boldsymbol{\Gamma} \mathbf{f}_{t}\right)=\boldsymbol{\Theta}\left(\mathbf{x}_{t-1}-\boldsymbol{\Gamma} \mathbf{f}_{t-1}\right)+\mathbf{u}_{t}
$$

where $\mathbf{x}_{t}$ is $k \times 1$ vector of endogenous variables, $\boldsymbol{\Gamma}$ is a $k \times m$ matrix of factor loadings, and $\mathbf{f}_{t}$ is an $m \times 1$ covariance stationary process of unobserved common factors. We consider one lag $(p=1)$ for simplicity of exposition. CP assume that $\varrho\left(\mathbf{\Theta \Theta}^{\prime}\right)<1-\epsilon$, where $\epsilon>0$ is an arbitrary small constant that does not depend on $N$, and $\mathbf{u}_{t}$ is weakly cross sectionally dependent such that $\left\|E\left(\mathbf{u}_{t} \mathbf{u}_{t}^{\prime}\right)\right\|=\left\|\boldsymbol{\Sigma}_{u}\right\|<K$. The condition that the spectral radius of $\boldsymbol{\Theta}^{\prime}$ is below and bounded

\footnotetext{
${ }^{8}$ Data-dependent rules to construct weights $\left\{\tilde{\mathbf{W}}_{i}\right\}$ are considered in Gross (2013).

${ }^{9}$ One exception is Chudik and Smith (2013) who consider the model $\boldsymbol{\Theta}(L)\left(\mathbf{x}_{t}-\boldsymbol{\Gamma} \mathbf{f}_{t}\right)=\mathbf{D} \boldsymbol{\xi}_{t}$, and allow for unit roots in $\mathbf{f}_{t}$ and $\boldsymbol{\xi}_{t}$, while assuming the roots of $\boldsymbol{\Theta}(L)=\mathbf{I}_{k}-\sum_{\ell=0}^{p} \mathbf{\Phi}_{\ell} L^{\ell}$ lie outside the unit circle.
} 
away from unity is a slightly stronger requirement than the usual stationarity requirement that the eigenvalues of $\boldsymbol{\Theta}$ are within the unit circle. The stronger condition is needed to ensure that variances exist when $N \rightarrow \infty$, as can be seen from the following illustrative example.

Example 1 Consider the following simple VAR(1) model,

$$
\mathbf{x}_{t}=\Theta \mathbf{x}_{t-1}+\mathbf{u}_{t}
$$

Let

$$
\underset{N \times N}{\boldsymbol{\Theta}}=\left(\begin{array}{ccccc}
\alpha & 0 & 0 & \cdots & 0 \\
\beta & \alpha & 0 & \cdots & 0 \\
0 & \beta & \alpha & & 0 \\
\vdots & & \ddots & \ddots & \\
0 & 0 & & \beta & \alpha
\end{array}\right),
$$

and suppose that $\mathbf{u}_{t} \sim \operatorname{IID}\left(0, \mathbf{I}_{N}\right)$. Hence, we have

$$
\begin{aligned}
& x_{1 t}=\alpha x_{1, t-1}+u_{1 t} \\
& x_{i t}=\beta x_{i-1, t-1}+\alpha x_{i, t-1}+u_{i t}, \text { for } i=2,3, \ldots, N .
\end{aligned}
$$

This model is stationary for any given $N \in \mathbb{N}$, if and only if $|\alpha|<1$. Nevertheless, the stationarity condition $|\alpha|<1$ is not sufficient to ensure that the variance of $x_{N t}$ is bounded in $N$ and without additional conditions $\operatorname{Var}\left(x_{N t}\right)$ can rise with $N$. To see this, note that

$$
\begin{aligned}
x_{1 t}= & (1-\alpha L)^{-1} u_{1 t}, \\
x_{2 t}= & (1-\alpha L)^{-2} \beta L u_{1 t}+(1-\alpha L)^{-1} u_{2 t}, \\
& \vdots \\
x_{N t}= & \sum_{j=1}^{N}(1-\alpha L)^{-N-1+j} \beta^{N-j} L^{N-j} u_{j t} .
\end{aligned}
$$


Let $\lambda=\beta^{2} /\left(1-\alpha^{2}\right)$, and note that

$$
\begin{aligned}
\operatorname{Var}\left(x_{1 t}\right)= & 1 /\left(1-\alpha^{2}\right) \\
\operatorname{Var}\left(x_{2 t}\right)= & \frac{1}{1-\alpha^{2}}(\lambda+1), \\
& \vdots \\
\operatorname{Var}\left(x_{N t}\right)= & \frac{1}{1-\alpha^{2}}\left(\lambda^{N-1}+\lambda^{N-2}+\ldots+\lambda+1\right) .
\end{aligned}
$$

The necessary and sufficient condition for $\operatorname{Var}\left(x_{N t}\right)$ to be bounded in $N$ is given by $\alpha^{2}+\beta^{2}<1$. Therefore, the condition $|\alpha|<1$ is not sufficient if $N \rightarrow \infty$. The condition $\varrho\left(\boldsymbol{\Theta}^{\prime}\right)<1-\epsilon$ for arbitrarily small $\epsilon$ that does not change with $N$ imply $\alpha^{2}+\beta^{2}<1$, and is therefore sufficient (and in this example it is also necessary) for $\operatorname{Var}\left(x_{N t}\right)$ to be bounded in $N$.

Similarly, as in DdPS, it is assumed in (27) that factors are included in the VAR model in an additive way so that $\mathbf{x}_{t}$ can be written as

$$
\mathbf{x}_{t}=\boldsymbol{\Gamma} \mathbf{f}_{t}+\boldsymbol{\xi}_{t}
$$

where $\boldsymbol{\xi}_{t}=\left(\mathbf{I}_{k}-\boldsymbol{\Theta} L\right)^{-1} \mathbf{u}_{t}$, and the existence of the inverse of $\left(\mathbf{I}_{k}-\boldsymbol{\Theta} L\right)$ is ensured by the assumption on $\varrho\left(\boldsymbol{\Theta}^{\prime}\right)$ above. One could also consider the alternative factor augmentation setup,

$$
\mathbf{x}_{t}=\boldsymbol{\Theta} \mathbf{x}_{t-1}+\boldsymbol{\Gamma} \mathbf{f}_{t}+\mathbf{u}_{t}
$$

where factors are added to the errors of the VAR model, instead of (27), where deviations of $\mathbf{x}_{t}$ from the factors are modelled as a VAR. But it is important to note that both specifications, (27) and (29), yield similar asymptotic results. The only difference would be that the factor error structure in (29) would result in distributed lag polynomials of infinite orders in large $N$ representation for cross-section averages and individual units. These lag polynomials would then need to be appropriately truncated for the purpose of consistent estimation and inference, as in Berk (1974), Said and Dickey (1984) and Chudik and Pesaran (2013a and 2013b). 
For any set of weights represented by the $k \times k^{*}$ matrix $\tilde{\mathbf{W}}_{i}$ we obtain (using (28))

$$
\mathbf{x}_{i t}^{*}=\tilde{\mathbf{W}}_{i}^{\prime} \mathbf{x}_{t}=\boldsymbol{\Gamma}_{i}^{*} \mathbf{f}_{t}+\boldsymbol{\xi}_{i t}^{*}
$$

where $\boldsymbol{\Gamma}_{i}^{*}=\tilde{\mathbf{W}}_{i}^{\prime} \boldsymbol{\Gamma}$ and

$$
\boldsymbol{\xi}_{i t}^{*}=\tilde{\mathbf{W}}_{i}^{\prime}\left(\mathbf{I}_{k}-\Theta L\right)^{-1} \mathbf{u}_{t}
$$

CP show that if $\tilde{\mathbf{W}}_{i}$ satisfies (24), then

$$
\begin{aligned}
\left\|E\left(\boldsymbol{\xi}_{i t}^{*} \boldsymbol{\xi}_{i t}^{* \prime}\right)\right\| & =\left\|\sum_{\ell=0}^{\infty} \tilde{\mathbf{W}}_{i}^{\prime} \Theta^{\ell} E\left(\mathbf{u}_{t-\ell} \mathbf{u}_{t-\ell}^{\prime}\right) \Theta^{\ell} \tilde{\mathbf{W}}_{i}\right\| \\
& \leq\left\|\tilde{\mathbf{W}}_{i}\right\|^{2}\left\|\boldsymbol{\Sigma}_{u}\right\| \sum_{\ell=0}^{\infty}\left\|\Theta^{\ell}\right\|^{2} \\
& =O\left(N^{-1}\right),
\end{aligned}
$$

where $\left\|\tilde{\mathbf{W}}_{i}\right\|^{2}=O\left(N^{-1}\right)$ by $(24),\left\|\boldsymbol{\Sigma}_{u}\right\|<K$ by the weak cross section dependence assumption, and $\sum_{\ell=0}^{\infty}\left\|\Theta^{\ell}\right\|^{2}<K$ by the assumption on spectral radius of $\varrho\left(\boldsymbol{\Theta}^{\prime}\right)$. (30) establishes that $\boldsymbol{\xi}_{i t}^{*} \stackrel{q . m .}{\rightarrow} \mathbf{0}$ (uniformly in $i$ and $t$ ) as $N, T \stackrel{j}{\rightarrow} \infty$. It now follows that

$$
\mathbf{x}_{i t}^{*}-\boldsymbol{\Gamma}_{i}^{*} \mathbf{f}_{t} \stackrel{q . m .}{\rightarrow} \mathbf{0}, \text { as } N, T \stackrel{j}{\rightarrow} \infty
$$

which confirms the well known result that only strong cross-section dependence can survive large $N$ aggregation with granular weights. ${ }^{10}$ Therefore the unobserved common factors can be approximated by cross section averages $\mathbf{x}_{t}^{*}$ in this dynamic setting, provided that $\boldsymbol{\Gamma}_{i}^{*}$ has full column rank.

Now it is easy to see what additional requirements are needed on the coefficient matrix $\Theta$ to obtain country VARX* models in (3) when $N$ is large. The model for the country specific variables, $\mathbf{x}_{i t}$, from the system (27) is given by

$$
\mathbf{x}_{i t}=\boldsymbol{\Theta}_{i i} \mathbf{x}_{i t-1}+\sum_{j=1, j \neq i} \boldsymbol{\Theta}_{i j}\left(\mathbf{x}_{j, t-1}-\boldsymbol{\Gamma}_{j} \mathbf{f}_{t}\right)+\boldsymbol{\Gamma}_{i} \mathbf{f}_{t}-\boldsymbol{\Theta}_{i}^{\prime} \boldsymbol{\Gamma}_{i} f_{t-1}+\mathbf{u}_{i t}
$$

\footnotetext{
${ }^{10}$ See for instance Granger (1987), Forni and Lippi (1997), Pesaran (2003), Zaffaroni (2004) and Pesaran (2006).
} 
where $\boldsymbol{\Theta}_{i j}$ are appropriate partitioned submatrices of

$$
\boldsymbol{\Theta}=\left(\begin{array}{cccc}
\boldsymbol{\Theta}_{11} & \boldsymbol{\Theta}_{12} & \cdots & \boldsymbol{\Theta}_{1 N} \\
\Theta_{21} & \boldsymbol{\Theta}_{22} & & \boldsymbol{\Theta}_{2 N} \\
\vdots & & \ddots & \vdots \\
\Theta_{N 1} & \Theta_{N 2} & \cdots & \boldsymbol{\Theta}_{N N}
\end{array}\right)
$$

Suppose now that

$$
\left\|\Theta_{i j}\right\|<\frac{K}{N} \text {, for all } i \neq j
$$

This assumption implies that the matrix $\boldsymbol{\Theta}_{-i}=\left(\boldsymbol{\Theta}_{i 1}, \boldsymbol{\Theta}_{i 2}, \ldots, \boldsymbol{\Theta}_{i, i-1}, 0, \boldsymbol{\Theta}_{i, i+1}, \ldots, \boldsymbol{\Theta}_{i N}\right)^{\prime}$ satisfies the granularity condition (24), in particular $\left\|\Theta_{-i}\right\|^{2}<K N^{-1}$, and using (30) but with $\Theta_{-i}$ instead of $\tilde{\mathbf{W}}_{i}$, we obtain

$$
\sum_{j=1, j \neq i} \boldsymbol{\Theta}_{i j}\left(\mathbf{x}_{j, t-1}-\boldsymbol{\Gamma}_{j} \mathbf{f}_{t}\right) \stackrel{q . m .}{\rightarrow} \mathbf{0} \text { as } N \rightarrow \infty
$$

Finally, substituting (31) and (34) in (32) we obtain the country specific VARX* $(1,1)$ model

$$
\mathbf{x}_{i t}-\boldsymbol{\Theta}_{i i} \mathbf{x}_{i t-1}-\boldsymbol{\Lambda}_{i 0} \mathbf{x}_{t}^{*}-\boldsymbol{\Lambda}_{i 1} \mathbf{x}_{t-1}^{*}-\mathbf{u}_{i t} \stackrel{q . m .}{\rightarrow} \mathbf{0} \text { uniformly in } i, \text { and as } N \rightarrow \infty
$$

where

$$
\boldsymbol{\Lambda}_{i 0}=\boldsymbol{\Gamma}_{i}\left(\boldsymbol{\Gamma}^{* \prime} \boldsymbol{\Gamma}^{*}\right)^{-1} \boldsymbol{\Gamma}^{*}, \text { and } \boldsymbol{\Lambda}_{i 1}=\boldsymbol{\Theta}_{i}^{\prime} \boldsymbol{\Gamma}_{i}\left(\boldsymbol{\Gamma}^{* \prime} \boldsymbol{\Gamma}^{*}\right)^{-1} \boldsymbol{\Gamma}^{*}
$$

Requirement (33) with the remaining assumptions in this subsection are thus sufficient to obtain (3) when $N$ is large. In addition to the derivations of large $N$ representations of the individual country models, CP also show that the coefficient matrices $\boldsymbol{\Theta}_{i i}, \boldsymbol{\Lambda}_{i 0}$ and $\boldsymbol{\Lambda}_{i 1}$ can be consistently estimated under the joint asymptotics when $N$ and $T \rightarrow \infty$, jointly, plus a number of further assumptions as set out in CP.

It is also important to consider the consequences of relaxing the restrictions in (33). One interesting case is when units have "neighbors" in the sense that there exists some country pairs $j \neq i$ for which $\left\|\Theta_{i j}\right\|$ remains non-negligible as $N \rightarrow \infty$. Another interesting departure from the above assumptions is when $\left\|\boldsymbol{\Sigma}_{u}\right\|$ is not bounded in $N$, and there exists a dominant unit $j$ for which $\left\|\boldsymbol{\Theta}_{i j}\right\|$ is non-negligible for the other units, $i \in S_{j} \subseteq\{1,2, \ldots, N\}$. These scenarios are 
investigated in Chudik and Pesaran (2011) and Chudik and Pesaran (2013b), and they lead to different specifications of the country-specific models featuring additional variables and parameters to be estimated. In such cases to improve estimation and inference one could combine the GVAR approach with various penalized shrinkage methods such as Bayesian shrinkage, Lasso or other related techniques where the estimation is subject to penalty, which becomes increasingly more binding as the number of parameters is increased. ${ }^{11}$

\section{Conducting Impulse Response Analysis with GVARs}

We have seen that under plausible conditions country-specific models can be obtained as large $N$ approximations to global factor augmented models of different forms. Moreover, individual countryspecific models can be consistently estimated. In this section, we discuss impulse response analysis and consistent estimation of generalized impulse responses.

For expositional convenience suppose that the DGP is given by (9) first. This model features $k=\sum_{i=1}^{N} k_{i}$ country-specific errors collected in the vector $\varepsilon_{t}=\left(\varepsilon_{1 t}^{\prime}, \varepsilon_{2 t}^{\prime}, \ldots, \varepsilon_{N t}^{\prime}\right)^{\prime}$, and there are no common variables included in the model. Suppose also that there are $k$ distinct structural (orthogonal) shocks. Identification of structural shocks, defined by $\mathbf{v}_{t}=\mathbf{P}^{-1} \varepsilon_{t}$, requires finding the $k \times 1$ matrix of contemporaneous dependence, $\mathbf{P}$, such that

$$
\boldsymbol{\Sigma}=\mathbf{E}\left(\varepsilon_{\mathbf{t}} \varepsilon_{\mathbf{t}}^{\prime}\right)=\mathbf{P P}^{\prime}
$$

Therefore, We have $E\left(\mathbf{v}_{t} \mathbf{v}_{t}^{\prime}\right)=\mathbf{I}_{k}$ by construction and the vector of structural impulse response functions is given by

$$
\begin{aligned}
\mathbf{g}_{v j}(h) & =E\left(\mathbf{x}_{t+h} \mid v_{j t}=1, \mathcal{I}_{t-1}\right)-E\left(\mathbf{x}_{t+h} \mid \mathcal{I}_{t-1}\right), \\
& =\frac{\mathbf{R}_{h} \mathbf{G}_{0}^{-1} \mathbf{P} \mathbf{e}_{j}}{\sqrt{\mathbf{e}_{j}^{\prime} \mathbf{\Sigma} \mathbf{e}_{j}}}
\end{aligned}
$$

\footnotetext{
${ }^{11}$ See for instance Tibshirani (1996), Hastie et al. (2009) and De Mol et al. (2008) for a discussion of Lasso and Ridge shrinkage methods. Feldkircher et al. (2014) implemented a number of Bayesian priors (the normal-conjugate prior, a non-informative prior on the coefficients and the variance, the inverse Wishart prior, the Minnesota prior, the single-unit prior, which accommodates potential cointegration relationships, and the stochastic search variable selection prior) in estimating country-specific models in the GVAR.
} 
for $j=1,2, \ldots, k$, where $\mathcal{I}_{t}=\left\{\mathbf{x}_{t}, \mathbf{x}_{t-1}, \ldots\right\}$ is the information set consisting of all available information at time $t$, and $\mathbf{e}_{j}$ is a $k \times 1$ selection vector that selects the variable $j$, and the $k \times k$ matrices, $\mathbf{R}_{h}$, are obtained recursively as

$$
\mathbf{R}_{h}=\sum_{\ell=1}^{p} \mathbf{F}_{\ell} \mathbf{R}_{h-\ell} \text { with } \mathbf{R}_{0}=\mathbf{I}_{k} \text { and } \mathbf{R}_{\ell}=\mathbf{0} \text { for } \ell<0
$$

Expectation operators in (37) are taken assuming that the GVAR model (9) is the DGP. Decomposition (36) is not unique and identification of shocks requires $k(k-1) / 2$ restrictions, which is of order $O\left(k^{2}\right) .{ }^{12}$ Even for moderate values of $k$, motivating such a large number of restrictions is problematic, especially given that the existing macroeconomic literature focuses mostly on distinguishing between different types of shocks (e.g. monetary policy shocks, fiscal shocks, technology shocks, etc.), and does not provide a thorough guidance on how to identify country origins of shocks, which is necessary to identify all the shocks in the GVAR model.

One possible approach to the identification of the shocks is orthogonalized IR analysis of Sims (1980), who considered setting $\mathbf{P}$ to the Choleski factor of $\boldsymbol{\Sigma}$. But as is well known the choice of the Choleski factor is not unique and depends on the ordering of variables in the vector $\mathbf{x}_{t}$. Such an ordering is clearly difficult to entertain in the global setting, but partial ordering could be considered to identify a single shock or a subset of shocks. This is, for example, accomplished by Dées et al. (2007) who identify the US monetary policy shock (by assuming that the US variables come first, and two different orderings for the vector of the US variables are considered). Another well-known possibility to identify shocks in reduced-form VARs include the work of Bernanke (1986), Blanchard and Watson (1986) and Sims (1986) who considered a priori restrictions on the contemporaneous covariance matrix of shocks; Blanchard and Quah (1989) and Clarida and Gali (1994) who consider restrictions on the long-run impact of shocks to identify the impulse responses; and the sign-restriction approach considered, among others, in Faust (1998), Canova and Pina (1999), Canova and de Nicoló (2002), Uhlig (2005), Mountford and Uhlig (2009) and Inoue and Kilian (2013). Identification of shocks in a GVAR is subject to the same issues as in standard VARs, but is further complicated due to the cross-country interactions and the high dimensionality of the model.

\footnotetext{
${ }^{12}$ This corrects the statement on p. 136 in Pesaran et al. (2004).
} 
In view of these difficulties, Pesaran et al. (2004), Pesaran and Smith (2006), Dées et al. (2007) and the subsequent literature adopted mainly the generalized IRF (GIRF) approach, advanced in Koop et al. (1996), Pesaran and Shin (1998) and Pesaran and Smith (1998). The GIRF approach does not aim at identification of shocks according to some canonical system or a priori economic theory, but considers a counterfactual exercise where the historical correlations of shocks are assumed as given. In the context of the GVAR model (9) the $k \times 1$ vector of GIRFs is given by

$$
\begin{aligned}
\mathbf{g}_{\varepsilon j}(h) & =E\left(\mathbf{x}_{t+h} \mid \varepsilon_{j t}=\sqrt{\sigma_{j j}}, \mathcal{I}_{t-1}\right)-E\left(\mathbf{x}_{t+h} \mid \mathcal{I}_{t-1}\right), \\
& =\frac{\mathbf{R}_{h} \mathbf{G}_{0}^{-1} \boldsymbol{\Sigma} \mathbf{e}_{j}}{\sqrt{\mathbf{e}_{j}^{\prime} \boldsymbol{\Sigma} \mathbf{e}_{j}}}
\end{aligned}
$$

for $j=1,2, \ldots, k, h=0,1,2, \ldots$, where $\sqrt{\sigma_{j j}}=\sqrt{E\left(\varepsilon_{j t}^{2}\right)}$ is the size of the shock, which is set to one standard deviation (s.d.) of $\varepsilon_{j t}$. The GIRFs can also be obtained for (synthetic) 'global' or 'regional' shocks, defined by $\varepsilon_{m, t}^{g}=\mathbf{m}^{\prime} \varepsilon_{t}$, where the vector of weights, $\mathbf{m}$, relates to a global aggregate or a particular region. GIRF vector for the global shock, $\varepsilon_{m, t}^{g}$, is

$$
\begin{aligned}
\mathbf{g}_{m}(h) & =E\left(\mathbf{x}_{t+h} \mid \varepsilon_{m, t}^{g}=\sqrt{\mathbf{m}^{\prime} \mathbf{\Sigma} \mathbf{m}}, \mathcal{I}_{t-1}\right)-E\left(\mathbf{x}_{t+h} \mid \mathcal{I}_{t-1}\right), \\
& =\frac{\mathbf{R}_{h} \mathbf{G}_{0}^{-1} \mathbf{\Sigma} \mathbf{m}}{\sqrt{\mathbf{m}^{\prime} \mathbf{\Sigma} \mathbf{m}}} .
\end{aligned}
$$

Now consider a GVAR model (19), which contains two types of shocks, $k$ country shocks in the vector $\varepsilon_{t}$, and $m_{\omega}$ common shocks in the vector $\boldsymbol{\eta}_{\omega t}$. Country shocks in $\varepsilon_{t}$ are uncorrelated with the common shocks $\boldsymbol{\eta}_{\omega t}$ due to the conditional nature of country models, which condition on contemporaneous and lagged values of the common variables, $\boldsymbol{\omega}_{t}$. The zero correlation between $\varepsilon_{t}$ and $\boldsymbol{\eta}_{\omega t}$ needs to be taken into account in the derivation of impulse responses. The vector of generalized impulse responses in the case of (19) is given by

$$
\begin{aligned}
\mathbf{g}_{\varepsilon_{y} j}(h) & =E\left(\mathbf{x}_{t+h} \mid \varepsilon_{y j t}=\sqrt{\sigma_{j j}}, \mathcal{I}_{t-1}\right)-E\left(\mathbf{x}_{t+h} \mid \mathcal{I}_{t-1}\right) \\
& =\frac{\mathbf{R}_{y h} \mathbf{G}_{y, 0}^{-1} \boldsymbol{\Sigma}_{y} \mathbf{e}_{y j}}{\sqrt{\mathbf{e}_{y j}^{\prime} \boldsymbol{\Sigma}_{y} \mathbf{e}_{y j}}}
\end{aligned}
$$

for $j=1,2, \ldots, k+m_{\omega}$ and $h=0,1,2, \ldots$, where $\mathbf{e}_{y j}$ is $\left(k+m_{\omega}\right) \times 1$ selection vector that selects 
$j$-th element, $\mathbf{R}_{y h}$ for $h=0,1,2, \ldots$, are $\left(k+m_{\omega}\right) \times\left(k+m_{\omega}\right)$ matrices obtained recursively as

$$
\begin{gathered}
\mathbf{R}_{y h}=\sum_{\ell=1}^{p} \mathbf{F}_{y \ell} \mathbf{R}_{y, h-\ell} \text { with } \mathbf{R}_{y, 0}=\mathbf{I}_{k+m_{\omega}} \text { and } \mathbf{R}_{y, \ell}=\mathbf{0} \text { for } \ell<0, \\
\boldsymbol{\Sigma}_{y}=E\left(\varepsilon_{y t} \varepsilon_{y t}^{\prime}\right)=\left(\begin{array}{cc}
\boldsymbol{\Sigma} & \mathbf{0} \\
\mathbf{0} & \boldsymbol{\Sigma}_{\omega}
\end{array}\right)
\end{gathered}
$$

$\boldsymbol{\Sigma}_{\omega}=E\left(\boldsymbol{\eta}_{\omega t} \boldsymbol{\eta}_{\omega t}^{\prime}\right)$, and as before $\boldsymbol{\Sigma}=E\left(\varepsilon_{t} \varepsilon_{t}^{\prime}\right)$. Similarly, one can consider generalized impulseresponse functions of a composite shock $\varepsilon_{y m, t}^{g}=\mathbf{m}_{y}^{\prime} \varepsilon_{y t}$, which could define a weighted average of country shocks in $\varepsilon_{t}$, or a weighted average of common shocks in $\boldsymbol{\eta}_{\omega t}{ }^{13}$

Closely related to the impulse-response analysis is the forecast-error variance decomposition, which shows the relative contributions of the shocks to reducing the mean square error of forecasts of individual endogenous variables at a given horizon $h$. In the case of orthogonalized shocks, $\mathbf{v}_{t}=\mathbf{P}^{-1} \varepsilon_{t}$, and assuming for the simplicity of exposition that $m_{\omega}=0$, the contribution of the $j$-th innovation $v_{j t}$ to the mean square error of the $h$-step ahead forecast of $x_{i t}$ is:

$$
\operatorname{SFEVD}\left(x_{i t}, v_{j t}, h\right)=\frac{\sum_{\ell=0}^{h}\left[\mathbf{e}_{i}^{\prime} \mathbf{F}^{h} \mathbf{G}_{0}^{-1} \mathbf{P} \mathbf{e}_{j}\right]^{2}}{\sum_{\ell=0}^{h} \mathbf{e}_{i}^{\prime} \mathbf{F}^{h} \mathbf{G}_{0}^{-1} \mathbf{\Sigma} \mathbf{G}_{0}^{-1 \prime} \mathbf{F}^{h \prime} \mathbf{e}_{i}}
$$

and since the shocks are orthogonal, it follows that $\sum_{j=1}^{N} \mathcal{S F E V D}\left(x_{i t}, v_{j t}, h\right)=1$ for any $i$ and $h$. In the case of non-orthogonal shocks, the forecast-error variance decompositions need not sum to unity. Analogously to the GIRFs, generalized forecast error variance decomposition of generalized shocks can be obtained as

$$
G \mathcal{F E} \mathcal{V D}\left(x_{i t}, \varepsilon_{j t}, h\right)=\frac{\sigma_{j j}^{-1} \sum_{\ell=0}^{h}\left[\mathbf{e}_{i}^{\prime} \mathbf{F}^{h} \mathbf{G}_{0}^{-1} \boldsymbol{\Sigma} \mathbf{e}_{j}\right]^{2}}{\sum_{\ell=0}^{h} \mathbf{e}_{i}^{\prime} \mathbf{F}^{h} \mathbf{G}_{0}^{-1} \mathbf{\Sigma}_{0}^{-1 /} \mathbf{F}^{h \prime} \mathbf{e}_{i}}
$$

\section{$6 \quad$ Forecasting with GVARs}

Forecasting is another important application of the GVAR approach, which provides a viable alternative to other methods developed for datasets with a large number of predictors. A difference

\footnotetext{
${ }^{13}$ Estimation and inference on impulse responses can be conducted by bootstrapping, see Dées et al. (2007) for details.
} 
between GVAR and other data-rich forecasting methods is that GVAR utilize the structure of the panel, which is assumed to consist of many cross-section units (e.g. countries) with each cross section unit consisting of a small number of variables. Other data-rich methods, such as Lasso, Ridge, or elastic net (see for instance Tibshirani (1996), De Mol et al. (2008) and Hastie et al. (2009)), popular factor models (Geweke (1977), Sargent and Sims (1977), and other contributions) ${ }^{14}$, or Partial Least Squares (Wold (1982)) typically do not utilize such structure. See Eklund and Kapetanios (2008) and Groen and Kapetanios (2008) for recent surveys of data-rich forecasting methods.

As in the previous section, we shall assume that the DGP is given by GVAR model (9). Taking conditional expectations of (9) for $t=t_{0}+h$ conditional on the information set $\Omega_{t_{0}}$, we obtain

$$
E\left(\mathbf{x}_{t_{0}+h} \mid \Omega_{t_{0}}\right)=\sum_{\ell=1}^{p} \mathbf{F}_{\ell} E\left(\mathbf{x}_{t_{0}+h-\ell} \mid \Omega_{t_{0}}\right)+\mathbf{G}_{0}^{-1} E\left(\varepsilon_{t_{0}+h} \mid \Omega_{t_{0}}\right),
$$

for any $h=0,1,2, \ldots$. In the case when the conditioning information set $\Omega_{t_{0}}$ is given by all available information up to the period $t_{0}, \Omega_{t_{0}}=\mathcal{I}_{t_{0}} \equiv\left\{\mathbf{x}_{t_{0}}, \mathbf{x}_{t_{0}-1}, \ldots\right\}$ we have

$$
E\left(\varepsilon_{t_{0}+h} \mid \mathcal{I}_{t_{0}}\right)=0 \text { for } h>0
$$

and standard forecasts $E\left(\mathbf{x}_{t_{0}+h} \mid \mathcal{I}_{t_{0}}\right)$ can be easily computed from (9) recursively using the estimates of $\mathbf{F}_{\ell}$ and $\mathbf{G}_{0}^{-1}$, and noting that (41) holds and $E\left(\mathbf{x}_{t^{\prime}} \mid \mathcal{I}_{t_{0}}\right)=\mathbf{x}_{t^{\prime}}$ for all $t^{\prime} \leq t_{0}$. Forecasts from model (19) featuring observed common variables can be obtained in a similar way.

Generating conditional forecasts for non-standard conditioning information sets with unbalanced information on (future, present and past values of) variables in the panel is more challenging. This situation could arise for instance in the case, where data for different variables are released at different dates, or when unbalanced information sets is intentionally considered to answer specific questions as in Bussière et al. (2012). Without loss of generality, and for expositional convenience, suppose, for some date $t^{\prime}$, that the first $k_{a}$ variables in the vector $\mathbf{x}_{t^{\prime}}$ belong to $\Omega_{t_{0}}$ and the last $k_{b}=k-k_{a}$ variables do not, and let us partition $\varepsilon_{t}$ as $\varepsilon_{t}=\left(\varepsilon_{a t}^{\prime}, \varepsilon_{b t}^{\prime}\right)^{\prime}$ and the covariance matrix

\footnotetext{
${ }^{14}$ See also Forni and Lippi (2001), Forni et al. (2000), Forni et al. (2004), Stock and Watson (1999), Stock and Watson (2002), Giannone, Reichlin, and Sala (2005), Bai and Ng (2007) and Stock and Watson (2005).
} 
$\boldsymbol{\Sigma}=E\left(\varepsilon_{t} \varepsilon_{t}^{\prime}\right)$ as

$$
\boldsymbol{\Sigma}=\left(\begin{array}{cc}
\boldsymbol{\Sigma}_{a a} & \boldsymbol{\Sigma}_{a b} \\
\boldsymbol{\Sigma}_{b a} & \boldsymbol{\Sigma}_{b b}
\end{array}\right)
$$

Then it follows that $E\left(\varepsilon_{a t^{\prime}} \mid \Omega_{t_{0}}\right)=\varepsilon_{a t^{\prime}}$, whereas $E\left(\varepsilon_{b t^{\prime}} \mid \Omega_{t_{0}}\right)=\boldsymbol{\Sigma}_{b a} \boldsymbol{\Sigma}_{a a}^{-1} \varepsilon_{a t^{\prime}}$. Let $\hat{\boldsymbol{\Sigma}}$ be an estimate of $\boldsymbol{\Sigma}$, then an estimate of $E\left(\varepsilon_{t^{\prime}} \mid \Omega_{m t_{0}}\right)$ can be computed as

$$
E \widehat{\left(\varepsilon_{t,} \mid \Omega_{t_{0}}\right)}=\left(\begin{array}{c}
\widehat{\varepsilon}_{a t^{\prime}} \\
\widehat{\Sigma}_{b a} \widehat{\Sigma}_{a a}^{-1} \widehat{\varepsilon}_{a t^{\prime}}
\end{array}\right)
$$

for any given $t^{\prime} \leq t_{0}+h$. The conditional forecasts $E\left(\mathbf{x}_{t_{0}+h} \mid \Omega_{t_{0}}\right)$ can then be computed recursively based on (40). One problem is that $\boldsymbol{\Sigma}$ and its four submatrices in (42) can have large dimensions relative to the available time sample and therefore it is not guaranteed that $\hat{\boldsymbol{\Sigma}}_{a a}$ is invertible. Even if it was, the inverse of the traditional estimate of variance-covariance matrices does not necessarily have good small sample properties when the number of variables is large. For these reasons, it is desirable to implement a covariance matrix with better small sample properties in the computation of conditional forecasts. There are several estimators proposed in the literature for estimation of high-dimensional covariance matrices, including Ledoit and Wolf (2004), Bickel and Levina (2008), Fan et al. (2008), Friedman et al. (2008), the shrinkage estimator considered in Dées et al. (2014), and the multiple testing approach by Bailey et al. (2014).

The implicit assumption in construction of the GVAR model (9) is invertibility of $\mathbf{G}_{0}$, which ensures that the model is complete as discussed in Subsection 3.1. If $\mathbf{G}_{0}$ is not invertible, then the system of country-specific equations is incomplete and it needs to be augmented with additional equations. This possibility is considered in Chudik, Grossman, and Pesaran (2014) who consider forecasting with GVARs in the case when $N, T \stackrel{j}{\rightarrow} \infty$, and the DGP is given by a factor-augmented infinite-dimensional VAR model of CP outlined in Section 4.2. For simplicity of exposition assume one variable per country $\left(k_{i}=1\right)$ and one unobserved common factor $(m=1)$ generated as

$$
f_{t}=\rho f_{t-1}+\eta_{f t}
$$

in which $|\rho|<1$ and the macro shock, $\eta_{f t}$, is serially uncorrelated and distributed with zero 
mean and variance $\sigma_{\eta}^{2}$. Let the factor loadings be denoted by $\gamma=\left(\gamma_{1}, \gamma_{2}, \ldots, \gamma_{N}\right)^{\prime}$, and consider a granular weights vector $\mathbf{w}=\left(w_{1}, w_{2}, \ldots, w_{N}\right)^{\prime}$ that defines the cross section averages $x_{i t}^{*}=x_{t}^{*}=\mathbf{w}^{\prime} \mathbf{x}_{t}$ (assumed to be identical across countries). Then (35) can be written as

$$
x_{i t}=\phi_{i i} x_{i, t-1}+\lambda_{i 0} x_{w t}^{*}+\lambda_{i 1} x_{w, t-1}^{*}+u_{i t}+O_{p}\left(N^{-1 / 2}\right), \text { for } i \in\{1,2, \ldots, N\},
$$

where $\lambda_{i 0}=\gamma_{i} / \gamma^{*}, \lambda_{i 1}=-\phi_{i i} \gamma_{i} / \gamma^{*}$, and $\gamma^{*}=\mathbf{w}^{\prime} \gamma$. Denote the corresponding least squares estimates of the unknown coefficients by hats, namely $\widehat{\phi}_{i i}, \widehat{\lambda}_{i 0}$ and $\widehat{\lambda}_{i 1}$. These estimates are consistent and asymptotically normally distributed (see CP). Note that (44) consists of $N$ different equations. Therefore, using estimates $\widehat{\phi}_{i i}, \widehat{\lambda}_{i 0}$ and $\widehat{\lambda}_{i 1}$, for $i=1,2, \ldots, N$, and provided that matrix $\widehat{\mathbf{G}}_{0}=\mathbf{I}_{N}-\operatorname{diag}\left(\hat{\boldsymbol{\lambda}}_{0}\right) \tilde{\mathbf{W}}^{\prime}$ is invertible, where $\tilde{\mathbf{W}}=\boldsymbol{\tau} \mathbf{w}^{\prime}, \boldsymbol{\tau}$ is $N \times 1$ vector of ones, one could obtain the following GVAR model

$$
\mathbf{x}_{t}=\widehat{\mathbf{F}} \mathbf{x}_{t-1}+\widehat{\mathbf{G}}_{0}^{-1} \widehat{\varepsilon}_{t}
$$

where $\widehat{\mathbf{F}}=\widehat{\mathbf{G}}_{0}^{-1} \widehat{\mathbf{G}}_{1}, \widehat{\mathbf{G}}_{1}=\hat{\mathbf{\Phi}}+\operatorname{diag}\left(\hat{\boldsymbol{\lambda}}_{1}\right) \tilde{\mathbf{W}}^{\prime}$, and $\hat{\mathbf{\Phi}}=\operatorname{diag}\left(\widehat{\phi}_{11}, \widehat{\phi}_{22}, \ldots, \widehat{\phi}_{N N}\right)$. However, it is not optimal to use (45) for forecasting in this set-up for the following two reasons. First, $\mathbf{G}_{0}=$ $\mathbf{I}_{N}-\operatorname{diag}\left(\hat{\boldsymbol{\lambda}}_{0}\right) \tilde{\mathbf{W}}^{\prime}$ is by construction rank deficient; to see this note that

$$
\begin{aligned}
\mathbf{w}^{\prime} \mathbf{G}_{0} & =\mathbf{w}^{\prime}\left[\mathbf{I}_{N}-\operatorname{diag}\left(\hat{\boldsymbol{\lambda}}_{0}\right) \tilde{\mathbf{W}}^{\prime}\right] \\
& =\mathbf{w}^{\prime}-\mathbf{w}^{\prime} \operatorname{diag}\left(\hat{\boldsymbol{\lambda}}_{0}\right) \boldsymbol{\tau} \mathbf{w}^{\prime}
\end{aligned}
$$

and recalling that $\sum_{i=1}^{N} w_{i} \gamma_{i}=\gamma^{*}$, we have

$$
\mathbf{w}^{\prime} \mathbf{G}_{0}=\mathbf{w}^{\prime}-\sum_{i=1}^{N}\left(\frac{w_{i} \gamma_{i}}{\gamma^{*}}\right) \mathbf{w}^{\prime}=\mathbf{w}^{\prime}-\mathbf{w}^{\prime}=\mathbf{0}^{\prime}
$$

which establishes that $\mathbf{G}_{0}$ has a zero eigenvalue. Since $\mathbf{G}_{0}$ is singular, the system of equations (44) is not complete and it is unclear what the properties of $\widehat{\mathbf{G}}_{0}^{-1}$ are, given that the individual elements of $\widehat{\mathbf{G}}_{0}$ are consistent estimates of the elements of $\mathbf{G}_{0}$. Second, the parameters in the conditional models $\left\{\phi_{i i}, \lambda_{i 0}, \lambda_{i 1}\right\}_{i=1}^{N}$ do not contain information about the persistence of unobserved common factor, $\rho$, due to the conditional nature of these models.

Chudik, Grossman, and Pesaran (2014) consider augmenting (44) with the following marginal 
equation for cross-section averages,

$$
x_{t}^{*}=\rho x_{t-1}^{*}+\gamma \eta_{f t}+O_{p}\left(N^{-1 / 2}\right) \text {, }
$$

where $x_{t}^{*}$ is treated as a proxy for the (scaled) unobserved common factor. See (31). Combining (44) and (46), they obtain the following VAR model in $\mathbf{z}_{t}=\left(\mathbf{x}_{t}^{\prime}, x_{t}^{*}\right)^{\prime}$,

$$
\mathbf{B}_{0} \mathbf{z}_{t}=\mathbf{B}_{1} \mathbf{z}_{t-1}+\mathbf{u}_{z t}+O_{p}\left(N^{-1 / 2}\right)
$$

where $\mathbf{u}_{z t}=\left(\mathbf{u}_{t}^{\prime}, \gamma \eta_{f t}\right)^{\prime}$

$$
\mathbf{B}_{0}=\left(\begin{array}{cc}
\mathbf{I}_{N} & -\boldsymbol{\lambda}_{0} \\
\mathbf{0}^{\prime} & 1
\end{array}\right), \mathbf{B}_{1}=\left(\begin{array}{cc}
\mathbf{\Phi} & \boldsymbol{\lambda}_{1} \\
\mathbf{0}^{\prime} & \rho
\end{array}\right)
$$

and $\boldsymbol{\Phi}$ is an $N \times N$ diagonal matrix with elements $\phi_{i i}$, for $i=1,2, \ldots, N$, on the diagonal. The matrix $\mathbf{B}_{0}$ is by construction invertible. Consider now the following forecast of $x_{i, t+h}$ conditional on $\mathcal{I}_{t}=\left\{\mathbf{x}_{t}, \mathbf{x}_{t-1}, \ldots\right\}$

$$
x_{i t h}^{f}=\tilde{\mathbf{e}}_{i}^{\prime} \mathbf{B}^{\ell} \mathbf{z}_{t},
$$

where $\mathbf{B}=\mathbf{B}_{0}^{-1} \mathbf{B}_{1}$, and $\tilde{\mathbf{e}}_{i}$ is an $N+1$ dimensional selection vector that selects the $i$-th element. Chudik, Grossman, and Pesaran (2014) establish that

$$
x_{i t h}^{f}=E\left(x_{i, t+h} \mid \mathcal{I}_{t}\right)+O_{p}\left(N^{-1 / 2}\right) \text {, }
$$

where the expectation operator is taken assuming $\mathbf{x}_{t}$ is given by a factor augmented infinitedimensional VAR model (27) with one factor given by (43), namely

$$
E\left(\mathbf{x}_{t+h} \mid \mathcal{I}_{t}\right)=\mathbf{\Theta}^{h} \mathbf{x}_{t}+\left(\rho^{h} \mathbf{I}_{N}-\mathbf{\Theta}^{\ell}\right) \gamma f_{t}
$$

This shows the large $N$ optimality of forecast $x_{i t h}^{f}$ defined in (48).

Even when $\mathbf{G}_{0}$ is invertible, it is possible that augmentation by equations for cross section averages can improve forecasting performance. Note that the GVAR model (9) does not feature an 
unobserved factor error structure. We have seen that a sufficient number of cross-section averages in the individual country-specific conditional models in (3) takes care of the effects of any strongly cross-sectionally dependent processes that enter as an unobserved common factors for the purpose of estimation of country-specific coefficients. Inclusion of a sufficient number of cross section averages will also lead to a weak cross section dependence of the vector of errors $\varepsilon_{t}$ in the country-specific models. But since the reduced form innovations $\mathbf{G}_{0}^{-1} \varepsilon_{t}$ must be strongly cross-sectionally dependent when a strong factor is present in $\mathbf{x}_{t}$, then it follows that $\mathbf{G}_{0}^{-1}$ (if it exists) cannot have bounded spectral matrix norm in $N$. Forecasts based on the augmented model avoid inversion of highdimensional matrices. Monte Carlo findings reported in Chudik, Grossman, and Pesaran (2014) suggest that augmentation of the GVAR by equations for cross section averages does not hurt when $\mathbf{G}_{0}$ is invertible while it can considerably improve forecasting performance when $\mathbf{G}_{0}$ is singular.

\subsection{Important issues in forecasting global economy}

There are two important issues in forecasting the global economy: the presence of structural breaks and model uncertainty. Structural breaks are quite likely, considering the diverse set of economies and the time period spanning three or more decades, which covers a lot of historical events (financial crises, wars, regime changes, natural disasters, etc.) The timing and the magnitude of breaks and the underlying DGP are not exactly known, which complicates the forecasting problem. Pesaran, Schuermann, and Smith (2009a) address both problems by using a forecast combination method. They considered simple averaging across selected models (AveM) and estimation windows (AveW) as well as across both dimensions, models and windows (AveAve); and obtain evidence of superior performance for their double-average (AveAve) forecasts. These and other forecasting evidence is reviewed in more detail in the next section. Forecast evaluation in the GVAR model is also challenging due to the fact that the multi-horizon forecasts obtained from the GVAR model could be cross-sectionally as well as serially dependent. One statistics to evaluate forecasting performance of the GVAR model is proposed by Pesaran, Schuermann, and Smith (2009a) who develop a panel version of the Diebold and Mariano (1995, DM) DM test assuming cross-sectional independence. 


\section{Long-run properties of GVARs}

\subsection{Analysis of long-run}

Individual country VARX* models in (3) allow for cointegration among domestic variables as well as among domestic and country-specific cross section averages of foreign variables. Let $\mathbf{z}_{i t}=\left(\mathbf{x}_{i t}^{\prime}, \mathbf{x}_{i t}^{* \prime}\right)^{\prime}$ be a $\left(k_{i}+k^{*}\right) \times 1$ vector of domestic and country-specific foreign variables for country $i$, and denote $r_{i}$ cointegrating relations among the variables in the vector $\mathbf{z}_{i t}$ as $\boldsymbol{\beta}_{i}^{\prime} \mathbf{z}_{i t}$, where $\boldsymbol{\beta}_{i}$ is a $\left(k_{i}+k^{*}\right) \times r_{i}$ dimensional matrix consisting of $r_{i}$ cointegrating vectors. The overall number of cointegrating vectors in the stacked GVAR model is naturally reflected in the eigenvalues of the companion representation of the GVAR model. These eigenvalues characterize the dynamic properties of the model which can also be used to examine the overall stability of the GVAR. In particular, when the overall number of cointegrating relations is $r=\sum_{i=1}^{N} r_{i}$, then $k-r$ eigenvalues of the GVAR model fall on the unit circle, and the remaining eigenvalues fall within the unit circle for the model to be stable.

\subsubsection{Testing for number of cointegrating vectors}

Testing for the number of cointegrating relations can be conducted using Johansen's trace and maximum eigenvalue test statistics as set out in Pesaran et al. (2000) for models with weakly exogenous $I(1)$ regressors. Small sample evidence typically suggests that the trace test performs better than the maximum eigenvalue test, but both are subject to usual size distortions when the time dimension is not sufficiently large. ${ }^{15}$ Selecting the number of cointegrating vectors is important, since misspecification of the rank of the cointegrating space can have severe impact on the performance of the resulting GVAR model, with adverse implications for stability, persistence profiles and impulse responses.

\subsubsection{Identification of long-run relations}

Once the number of cointegrating vectors is determined, it is possible to proceed with the identification of long-run structural relations and, if desired, to impose over-identifying restrictions. These

\footnotetext{
${ }^{15}$ The maximum eigenvalue test statistics is also less robust to departures from normal errors, see Cheung and Lai (1993) for a Monte Carlo evidence.
} 
restrictions can then be tested using the log-likelihood ratio test statistics. See Garratt et al. (2006) for a comprehensive review of long-run identification methods in macroeconometric literature. The first contribution on the identification of long-run relations in the GVAR literature is Dées, Holly, Pesaran, and Smith (2007) who used bootstrapping to compute critical values for the likelihood ratio tests of overidentifying restrictions on the long-run relations of the country-specific models.

\subsubsection{Persistence profiles}

The speed of convergence with which the adjustment to long-run relations takes place in the global model can be examined by persistence profiles (PPs). PPs refer to the time profiles of the effects of system or variable-specific shocks on the cointegrating relations and they provide another valuable evidence on the validity of chosen long-run relations, see Pesaran and Shin (1996) for a discussion of PPs in cointegrated VAR models and Dées, Holly, Pesaran, and Smith (2007) for implementation of PPs in the GVAR.

\subsection{Permanent/transitory component decomposition}

Given that the GVAR model provides a coherent description of the short-run as well as long-run relations in the global economy, it can be used to provide estimates of steady-states or the permanent components of the variables in the GVAR model. Assuming no deterministic components are present, then the vector of permanent components is simply defined as long-horizon expectations:

$$
\mathbf{x}_{t}^{P}=\lim _{h \rightarrow \infty} E_{t}\left(\mathbf{x}_{t+h}\right) .
$$

In the case when deterministic components are present, $\mathbf{x}_{t}^{P}$ will be given by the sum of the deterministic components and long-horizon expectations of de-trended variables. The vector of deviations from steady states is in both cases given by

$$
\widetilde{\mathbf{x}}_{t}=\mathbf{x}_{t}-\mathbf{x}_{t}^{P}
$$


Assuming that the information set is non-decreasing over time, it follows from (50) that $\mathbf{x}_{t}^{P}=$ $\lim _{h \rightarrow \infty} E_{t}\left(\mathbf{x}_{t+h}^{P}\right)$, which ensures that the steady-states are time consistent, in the sense that

$$
E_{t}\left(\mathbf{x}_{t+s}^{P}\right)=\lim _{h \rightarrow \infty} E_{t}\left(\mathbf{x}_{t+s+h}^{P}\right)=\mathbf{x}_{t}^{P} \text { for any } s=0,1,2, \ldots
$$

and, in the absence of deterministic components, $\mathbf{x}_{t}^{P}$ satisfy the martingale property, $E_{t}\left(\mathbf{x}_{t+1}^{P}\right)=$ $\mathbf{x}_{t}^{P}$. Such a property is a natural requirement of any coherent definition of steady-states, but this property is not satisfied for the commonly used Hordick-Prescott (HP) filter and some of the other statistical measures of steady-states.

Permanent components can be easily obtained from the estimated GVAR model using the Beveridge-Nelson decomposition, as illustrated in detail by Dées, Holly, Pesaran, and Smith (2007). Estimates of steady-states are crucial for the mainstream macroeconomic literature, which focuses predominantly on modelling the business cycle, that is explaining the behavior of deviations from the steady-states. The GVAR provides a coherent method for constructing steady states that reflect global influences and long-run structural relationships within as well as across countries in the global economy.

\section{Specification tests}

It has become a norm in applied work to perform a number of specification tests and robustness checks. DdPS apply a suite of residual based break tests to test for the stability of coefficients and/or breaks in error variances. Although, in the context of cointegrated models, the possibility of a structural break is relevant for both long-run as well as short-run coefficients, the focus is on the stability of short-run coefficients, as the availability of data hinders any meaningful tests of the stability of cointegrating vectors. In particular, DdPS performed the following tests: Ploberger and Krämer (1992) maximal OLS cumulative sum (CUSUM) statistics; its mean square variant; Nyblom's (1989) tests for the parameter constancy against non-stationary alternatives; the Wald form of Quandt's (1960) likelihood ratio statistics; the mean Wald statistics of Hansen; and Andrews and Ploberger (1994) Wald statistics based on exponential average. The last three tests are Wald type tests utilizing a single break at an unknown point. The heterokedasticity-robust version of 
the tests were also conducted. Stability tests performed are based on residuals of the individual country models, which depend on the dimension of the cointegrating space, and do not require the cointegrating relationships to be identified. The critical values of the tests, computed under the null of parameter stability, can again be calculated using the sieve bootstrap samples. Details of the bootstrap procedure is given in DdPS (2007, Supplement A). In the context of global macroeconomic modelling, DdPS and other applied papers typically find, perhaps surprisingly, relatively small rejection rates, and the main reason for the rejection seems to be breaks in the error variances as opposed to coefficient instability. Once breaks in error variances are allowed for, the remaining parameters are typically reasonably stable.

A number of robustness checks could also be performed to test the sensitivity of the findings to variations of different assumptions, including lag selection, choice of the aggregation weights, selection of the number of cointegrating relations and possibly over-identifying long-run relations, sample selection, and similar robustness checks.

\section{Empirical applications of the GVAR approach}

Since the introduction of the GVAR model by Pesaran et al. (2004), there have been numerous applications of the GVAR approach developed over the last decade. The GVAR handbook edited by di Mauro and Pesaran (2013) provides an interesting collection of a number of GVAR empirical applications from 27 contributors. The GVAR handbook is a useful non-technical resource aimed at general audience and/or practitioners interested in the GVAR approach. This handbook provides a historical background of the GVAR approach (Chapter 1), describes an updated version of the basic DdPS model (Chapter 2), and then provides 7 applications of the GVAR approach on international transmission of shocks and forecasting (Chapters 3-9), 3 finance applications (Chapters 10-12), and 5 regional applications. The applications in the handbook span various areas of the empirical literature. Chapters on international transmission on forecasting investigate, among others, the problem of measuring output gaps across countries, structural modelling, the role of financial markets in the transmission of international business cycles, international inflation interlinkages, and forecasting the global economy. Finance applications include a macroprudential application of the GVAR approach, a model of sovereign bond spreads, and an analysis of cross-country spillover 
effects of fiscal spending on financial variables. Regional applications investigate the increasing importance of the Chinese economy, forecasting of the Swiss economy, imbalances in the Euro Area, regional and financial spillovers across Europe, and modelling interlinkages in the West African Economic and Monetary Union. We refer the reader to this Handbook for further details on these interesting applications.

The remainder of this section reviews the empirical literature using the GVAR approach focussing on the different types of questions being addressed. We separate forecasting applications from the other applications of the GVAR approach. We divide the latter literature depending on the definition of cross-section units into two broad categories: 'global' finance and macro applications, where units are individual countries, or countries grouped into regions, or a mixture of countries/regions and other cross-section units (so-called mixed cross-section GVARs), and 'sectoral and other' applications, in which the main cross-section units are sectors, individual consumer price categories, or other types of cross section units other than countries.

\subsection{Forecasting applications}

Pesaran, Schuermann, and Smith (2009a) is the first GVAR forecasting application to the global economy. These authors utilize the version of the GVAR model developed in DdPS and focus on forecasting real as well as financial variables, namely one and four quarters ahead forecasts for real output, inflation, real equity prices, exchange rates and interest rates. As we mentioned earlier in Section 6, forecasting the global economy is challenging due to the likely presence of multiple structural breaks and model uncertainty. The main finding of Pesaran, Schuermann, and Smith (2009a) is that simple averaging across model specifications and estimation windows can make a significant difference. In particular, the double-averaged GVAR forecasts (across windows and models) perform better than the typical univariate benchmark competitors, especially for output, inflation and real equity prices. Further forecasting results and discussions are presented in a rejoinder, Pesaran, Schuermann, and Smith (2009b).

Ericsson and Reisman (2012) provide an empirical assessment of the DdPS version of GVAR with an impulse indicator saturation technique, which is a new generic procedure for evaluating parameter constancy. Their results indicate the potential for an improved, more robust specification 
of the GVAR model.

Forecasting key South African variables with a GVAR is investigated in de Waal and van Eyden (2013a). This paper considers small and large versions of the GVAR model and compare GVAR forecasts with forecasts generated from a vector error correction model (VECM) augmented with foreign variables as well as with univariate benchmarks. De Waal and van Eyden find that modelling the rest-of-the-world economies in a coherent way using the GVAR model can be useful for forecasting domestic variables for South Africa. In particular, they find that forecast performance of the large version of the GVAR model is generally superior to the performance of the customized small GVAR, and that forecasts of both GVAR models tend to be better than the forecasts of the augmented VECM, especially at longer forecast horizons.

Forecasting regional labor markets with GVARs is undertaken in Schanne (2011) using German regional labor market data. Schanne focuses on the forecasting different labour market indicators and finds that including information about labor-market policies and vacancies, and accounting for the lagged and contemporaneous spatial dependence can improve the forecasts relative to a simple bivariate benchmark model. On the other hand, business-cycle indicators seem to have no information regarding labor-market predictions.

Conditional forecasting is considered in Bussière, Chudik, and Sestieri (2012), who apply a GVAR model to analyze global trade imbalances. In particular, they compare the growth rates of exports and imports of the 21 countries in the sample during the Great Trade Collapse of 2008-09 with the model's prediction, conditioning on the observed values of real output and real exchange rates. The objective of this exercise is to assess whether the collapse in world trade that took place during 2008-2009 can be rationalized by standard macro explanatory variables (domestic and foreign output as proxies for demand terms and real exchange rates as proxies for relative prices) alone or if other factors may have played a role. The standard macro explanatory variables alone are found to be quite successful in explaining the collapse of the global trade for most of the economies in the sample. This exercise also uncovers that it is easier to reconcile the Great Trade Collapse of 2008-09 in the case of advanced economies as opposed to emerging economies.

Forecasting of trade imbalances is also considered in Greenwood-Nimmo, Nguyen, and Shin (2012b). They compute both central forecasts and scenario-based probabilistic forecasts for a range 
of events and account for structural instability by use of country-specific intercept shifts identified by taking into account both statistical evidence and a priori knowledge of historic economic conditions and events. The authors find that predictive accuracy of the GVAR model is broadly comparable to that of standard benchmark models over short horizons and superior over longer horizons. Similarly to Bussière, Chudik, and Sestieri (2012), they conclude GVAR models may be a useful forecasting tool for policy institutions.

Nowcasting of global growth with GVARs is considered in Chudik, Grossman, and Pesaran (2014), who focus on the information content of timely purchasing manager indices (PMIs) for the nowcasting of growth. This exercise does take into account data release lags, and conditional forecasts for real output growth (conditional on the latest available unbalanced information at a given point in time) are derived. Moreover, the authors also consider averaging across estimation windows and Ridge estimation of the individual country models in the GVAR with the penalization/shrinkage parameter chosen by cross-validation. The GVAR based on individual country models estimated subject to the penalization constraint is often found to have better forecasting performance.

Improved forecasting performance of the GVAR model constructed based on country models estimated with shrinkage estimators is also reported in Feldkircher et al. (2014) who implemented a number of Bayesian priors in estimating country-specific models in the GVAR. In particular, they implemented the normal-conjugate prior, a non-informative prior on the coefficients and the variance, the inverse Wishart prior, the Minnesota prior, the single-unit prior, which accommodates potential cointegration relationships, and the stochastic search variable selection prior. While Bayesian estimation of the country models tends to improve the forecasting performance for all of the priors considered, the use of the stochastic search variable selection prior is found to improve out-of-sample predictions systematically.

Forecasting with a regime-switching GVAR model is considered in Binder and Gross (2013) who find that combining the regime-switching and the GVAR methodology improves out-of-sample forecast accuracy significantly in an application to real GDP, price inflation, and stock prices. 


\subsection{Global finance applications}

The first GVAR model in the literature, developed by PSW, is applied to the problem of credit risk modelling with a global perspective. PSW investigate the effects of various global risk scenarios on a bank's loan portfolio. The use of a GVAR model for modelling credit risk has also been explored in Pesaran, Schuermann, and Treutler (2007) who investigated the potential for portfolio diversification across industry sectors and across different countries and find that full firm-level parameter heterogeneity along with credit rating information matters a great deal for capturing differences in simulated credit loss distributions. Further results on the modelling of credit risk with a global perspective are provided by Pesaran, Schuermann, Treutler, and Weiner (2006). The GVAR based conditional credit loss distribution is used, for example, to compute the effects of a hypothetical negative equity price shock in South East Asia on the loss distribution of a credit portfolio with global exposures over one or more quarters ahead. Pesaran, Schuermann, Treutler, and Weiner (2006) find that the effects of such shocks on losses are asymmetric and nonproportional, reflecting the highly nonlinear nature of the credit risk model. de Wet, van Eyden, and Gupta (2009) develop a South African-specific component of the GVAR model for the purpose of credit portfolio management in South-Africa. Their set of domestic factors for South Africa is extended beyond those used in PSW in such a way to take into account both retail and corporate credit risk. Castrén, Dées, and Zaher (2010) use a GVAR to analyze the behavior of euro area corporate sector probabilities of default under a wide range of different shocks. They link the core GVAR model with a satellite equation for firm-level Expected Default Frequencies (EDFs) and find that, at the aggregate level, the median EDFs react most to shocks to GDP, exchange rate, oil prices and equity prices.

A number of other empirical GVAR papers focus on modelling various types of risk. Gray, Gross, Paredes, and Sydow (2013) analyze interactions between banking sector risk, sovereign risk, corporate sector risk, real economic activity, and credit growth for 15 European countries and the United States. The goal is to analyze the impact and spillover effects of shocks and to help identify policies that could mitigate banking system failures, sovereign credit risk and recession risk-policies including bank capital increases, purchase of sovereign debt, and guarantees. Alessandri, Gai, Kapadia, Mora, and Puhr (2009) develop a quantitative framework for gauging systemic risk which 
explicitly characterizes banks' balance sheets and allows for macro credit risk, interest income risk, market risk, network interactions, and asset-side feedback effects. Their core macro model is a 2-country version of the GVAR (UK as a small open economy and the US) and they focus on projections for system-wide banking assets in the United Kingdom and show how a combination of extreme credit and trading losses can precipitate widespread defaults and trigger contagious default associated with network effects and fire sales of distressed assets.

Dreger and Wolters (2011) investigate the implications of an increase in liquidity in the years preceding the global financial crises on the formation of price bubbles in asset markets. They find that the link between liquidity and asset prices seems fragile and far from being obvious. Implications of liquidity shocks and their transmission are also investigated in Chudik and Fratzscher (2011). In addition to liquidity shocks, Chudik and Fratzscher (2011) identify risk shocks and find that while liquidity shocks have had a more severe impact on advanced economies during the recent global financial crisis, it was mainly the decline in risk appetite that affected emerging market economies. The tightening of financial conditions was a key transmission channel for advanced economies, whereas for emerging markets it was mainly the real side of the economy that suffered. They also find some interesting differences over different types of economies, with Europe being more adversely affected by the fall in risk appetite than other advanced economies. Effects of risk shocks are also scrutinized in Bussière, Chudik, and Mehl (2011) for a monthly panel of real effective exchange rates featuring 62 countries. Bussière, Chudik, and Mehl (2011) find that the responses of real effective exchange rates of euro area countries to a global risk aversion shock after the creation of euro have become similar to those of Italy, Portugal or Spain before the European monetary union, i.e. of economies in the euro area's periphery. Moreover, their findings suggest that the divergence in external competitiveness among euro area countries over the last decade, which is at the core of today's debate on the future of the euro area, is more likely due to country-specific shocks than to global shocks. Dovern and van Roye (2013) use a GVAR to study the international transmission of financial stress and its effects on economic activity and find that financial stress is quickly transmitted internationally. Moreover, they find that financial stress has a lagged but persistent negative effect on economic activity, and that economic slowdowns induce only limited financial stress. 
Gross and Kok (2013) use a mixed-cross-section (23 countries and 41 international banks) GVAR specification to investigate contagion among sovereigns and banks. They find that spill-over potential in the credit default swap (CDS) market was particularly pronounced in 2008 and more recently in 2011-12. Moreover, contagion primarily tends to move from banks to sovereigns in 2008, whereas the direction seems to have been reversed in 2011-12 in the course of the sovereign debt crisis. Last but not least, their results indicate that the system of banks and sovereigns has become more closely connected over time.

Interrelation between volatility in financial markets on macroeconomic dynamics is investigated in Cesa-Bianchi, Pesaran, and Rebucci (2014), who extend the GVAR model of DdPS by a volatility module. Assuming that all variables are driven by the same set of unobserved common factors, and moreover these common factors affect the volatility and macroeconomic activity with a time lag of at least of a quarter (financial markets react instantaneously, whereas macroeconomic variables react with a lag). Under these assumption, Cesa-Bianchi, Pesaran, and Rebucci (2014) find a statistically significant and economically sizable impact of future output growth on current volatility, and no effect of an exogenous change in volatility on the business cycle over and above those driven by the common factors. They interpret this evidence as suggesting that volatility is a symptom rather a cause of economic instability.

\subsection{Global macroeconomic applications}

DdPS update the PSW GVAR model by expanding the country coverage (to 33 with 25 of these modelled separately and the remaining countries grouped into a single euro area economy) as well as the time coverage, and provide further theoretical results, some of which were reviewed above. Their focus is on the enhancement of the global model and its use to analyze transmission of shocks across countries with a particular attention on the implications for the euro area economy. Using variety of shocks, including shocks to US equity prices, oil prices, US short term interest rates, as well as US monetary policy shocks (identified by using partial ordering of variables), DdPS find that financial shocks are transmitted relatively rapidly and often get amplified as they travel from US to euro area. The impact of US monetary policy shocks on euro area is, however, rather limited. Effects of different shocks on the economy has also been the focus of many other papers reviewed 
below.

\subsubsection{Global inflation}

Galesi and Lombardi (2009) study the effects of oil and food price shocks on inflation. They find that the inflationary effects of oil price shocks are felt mostly in the developed countries while less sizeable effects are observed in the case of emerging economies. Moreover, food price increases also have significant inflationary direct effects, especially for emerging economies, and significant second-round effects are reported in some countries. Inflation is also the focus of Anderton, Galesi, Lombardi, and di Mauro (2010) who construct a GVAR model to examine oil price shocks and other key factors affecting global inflation. They consider calculating the impact of increased imports from low-cost countries on manufacturing import prices and estimate Phillips curves in order to shed light on whether the inflationary process in OECD countries has changed over time. They find that there seem to be various significant pressures on global trade prices and labor markets associated with structural factors, and argue that these are partly due to globalization which, in addition to changes in monetary policy, seem to be behind some of the changes in the inflationary process over the period under consideration.

Using the GVAR model, Dées, Pesaran, Smith, and Smith (2009) provide estimates of New Keynesian Phillips Curves (NKPC) for eight developed industrial countries and discuss the weak instrument problem and the characterization of the steady states. It is shown that the GVAR generates global factors that are valid instruments and help alleviate the weak instrument problem. Moreover, it is argued that the GVAR measures of the steady states perform better than the Hodrick-Prescott (HP) measure, and the use of foreign instruments substantially increases the precision of the estimates of the output coefficient in the NKPC equations.

\subsubsection{Global imbalances}

The effects of demand shocks and shocks to relative prices on global imbalances are examined in Bussière, Chudik, and Sestieri (2012)'s GVAR model of global trade flows. Their results indicate that changes in domestic and foreign demand have a much stronger effect on trade flows than 
changes in relative trade prices. Using the GVAR approach, global imbalances are also investigated, although with a different focus, in Bettendorf (2012).

\subsubsection{Role of US as a dominant economy}

The role of the US as a dominant economy in the world is examined in Chudik and Smith (2013) by comparing two models: one that treats US as a globally dominant economy, and a standard version of the GVAR model that does not separate the impact of US variables from the cross-section averages of foreign economies, as in DdPS. They find some support for the extended version of the GVAR model, allowing the US to be the dominant player in the world economy, but they had to restrict the set of variables in the GVAR model to only 4 (short-term interest rates, output, inflation and real exchange rates) in order to bring down the number of unknown parameters in the extended version of the GVAR model that treats US as a dominant economy. The role of the US as a potentially globally dominant economy and its evolution over time has also been investigated by Dées and Saint-Guilhem (2011) who model real output alone in a global setting and find that the role of US somewhat diminished over time.

\subsubsection{Business cycle synchronization and interdependence of a country (region) with the rest of the world economy}

Dreger and Zhang (2013) investigate interdependence of business cycles in China and industrial countries and study the effects of shocks to Chinese economy, particularly stemming from the recent fiscal stimulus package. Substantial impact on growth in the advanced economies and the Asian region are found. Moreover, China is found to be vulnerable to shocks in industrial countries as well.

Understanding the interdependence between China, Latin America and the world economy is the main goal of Cesa-Bianchi, Pesaran, Rebucci, and Xu (2012), who find that the long-term impact of a China GDP shock on the typical Latin American economy has increased by three times since mid-1990s. Moreover, the long-term impact of a US GDP shock has halved, while the transmission of shocks to Latin America and the rest of emerging Asia (excluding China and India) 
GDP has not undergone any significant changes. These findings are based on a GVAR model with time-varying trade weights, which altered the transmission mechanism, and they indicate that the emergence of China as an important source of world growth might be the driver of the so called "decoupling" of emerging markets business cycle from that of advanced economies reported in the literature.

The rise of China in the world economy and emerging markets in particular is also investigated in Feldkircher and Korhonen (2012). They find that a $+1 \%$ shock to Chinese output translates to a permanent increase of $1.2 \%$ in Chinese real GDP and a $0.1 \%$ to $0.5 \%$ rise in output in the case of large economies. The countries of Central Eastern Europe and the former Commonwealth of Independent States also experience an output rise of $0.2 \%$, while countries in South-Eastern Europe see a permanent $0.1 \%$ reduction in output. By contrast China seems to be little affected by shocks to the US economy. Feldkircher and Korhonen (2012) also find that Russia's real output increases by about $6 \%$ following a $50 \%$ hike in oil prices, whereas the surge in oil prices decreases Chinese output by $4.5 \%$ in the long-run.

Understanding the Latin America business cycle is the goal of Dreger and Zhang (2013). In a 9 country/region version of the GVAR, they quantify the relative contribution of domestic, regional and international factors to the fluctuation of domestic output in Latin American countries. In particular, they find that only a modest proportion of LA countries' domestic output variability is explained by industrial countries' factors and that domestic and regional factors account for the main share of output variability at all simulation horizons.

International linkages of the Korean economy are investigated in Greenwood-Nimmo, Nguyen, and Shin (2012a). They uncover that the real economy and the financial markets are highly sensitive to the oil price changes even though it has little effect on inflation and that the interest rate is set largely without recourse to overseas conditions except to the extent that they are captured by the exchange rate. They find that the Korean economy is most affected by US, the eurozone, Japan and China.

Understanding interlinkages between the Emerging Europe and the global economy is investigated in Feldkircher (2013) who develop a GVAR model covering 43 countries. The main findings are that the Emerging Europe's real economy reacts to a US output shock as strongly as it does 
to a corresponding euro area shock. Moreover, Feldkircher (2013) uncovers a negative effect of tightening in the euro area's short-term interest rate on output in the long run throughout the Central, Eastern and Southeastern Europe and the Commonwealth of Independent States.

Sun, Heinz, and Ho (2013) use the GVAR approach with combined trade and financial weights to investigate cross-country linkages in Europe. Their findings show strong co-movements in output growth and interest rates but weaker linkages between inflation and real credit growth within Europe.

The impact of foreign shocks on South Africa is studied in de Waal and van Eyden (2013b). Using time-varying weights they uncover increasing role of China and decreasing role of the US, reflecting the substantial increase in South Africa's trade with China since the mid-1990s. The impact of a US shock on South African GDP is found to be insignificant by 2009, whereas impact of a shock to Chinese GDP on South African GDP is found to be three times stronger in 2009 than in 1995. These findings are in line with the way the global crisis of 2007-09 affected South Africa, and highlight increased risk to the South African economy from shocks to Chinese economy.

\subsubsection{Impact of EMU membership}

Two papers, Pesaran, Smith, and Smith (2007) and Dubois, Hericourt, and Mignon (2009) investigate counterfactual scenarios of a monetary union membership. Pesaran, Smith, and Smith (2007) provide a conceptual framework to analyze counterfactual scenarios using macroeconometric models and investigate empirically the consequences of a scenario where UK joins Euro in 1999. They report probability estimates that output could have been higher and prices lower in the UK and in the euro area as a result of entry, and they also examine the sensitivity of these results to a variety of assumptions about UK entry. The aim of Dubois, Hericourt, and Mignon (2009) is to answer the counterfactual question of the consequences of no euro launch in 1999. They find that monetary unification promoted lower interest rates and higher output in most euro area economies, relative to a situation where national monetary policies would have followed a German-type monetary policy. An opposite picture emerges if national monetary policies had adopted British monetary preferences after September 1992. 


\subsubsection{Commodity price models}

Gutierrez and Piras (2013) construct a GVAR model of global wheat market. Due to the nature of the GVAR approach, the feedback between the real and the financial sectors and also the link between food and energy prices can be taken into account. Their impulse response analysis reveals that a decrease of wheat stocks with respect to the level of consumption, and an increase in oil prices, and real exchange rate devaluation have all inflationary effects on wheat export prices, although their impacts are different across the main export countries.

While oil prices are included in majority of GVAR models as an important observed common factor, these studies generally do not focus on the nature of oil shocks and their effects. Identification of oil shocks is attempted in Chudik and Fidora (2012) and Cashin, Mohaddes, Raissi, and Raissi (2014). Both papers argue that the cross section dimension can help in the identification of (global) oil shocks and utilize a set of sign restrictions. The former paper investigates the effects of oil supply driven increases in oil prices on output and real effective exchange rates and find that adverse oil supply shocks have significant negative impact on real output growth of oil importers within which emerging markets tend to be more affected as compared with the more mature economies. Moreover, oil supply shocks tend to cause an appreciation (depreciation) of oil exporters' (oil importers') real effective exchange rates but also lead to an appreciation of the U.S. dollar. Cashin, Mohaddes, Raissi, and Raissi (2014) identify both demand as well as supply shocks and find that economic consequences of the two types of shocks are very different. They also find negative impacts of adverse oil supply shocks for energy importers, while the impacts on oil exporters that possess large proven oil/gas reserves is positive. A positive oil-demand shock, on the other hand, is found to be associated with long-run inflationary pressures, an increase in real output, a rise in interest rates, and a fall in equity prices in almost all countries in their sample.

\subsubsection{Housing}

Jannsen (2010) investigates the international effects of housing crises, focusing on US, Great Britain, Spain and France. Among other findings, Jansen's results show that on average a housing crisis has the most severe effects in the first two years - particularly between the fifth and the seventh quarter after the house prices have reached their peak, and the output gap is not expected to close 
within five years. However, when several important industrial countries face a housing bust at the same time, economic activity in other countries is likely to be dampened as well via international transmission effects, leading to significant losses of GDP growth in a number of countries, notably in Europe.

Hiebert and Vansteenkiste (2009) adopt the GVAR approach to investigate house price spillovers across euro area countries, using three housing demand variables: real house prices, real per capita disposable income, and the real interest rate for 10 euro area countries. Their results suggest limited house price spillovers in the euro area, in contrast with the impacts of a shock to domestic long-term interest rates, with the latter causing a permanent shift in house prices after around 3 years. Moreover, house price spillovers are found to be quite heterogenous across countries.

\subsubsection{Effects of fiscal policy}

International effects of fiscal policy shocks is examined in Favero, Giavazzi, and Perego (2011) using the GVAR approach. These authors argue that effects of fiscal policy on output differs depending on the different debt dynamics, the different degree of openness, and the different fiscal reaction functions across countries. Such heterogeneities concern not only the size of the fiscal multiplier, but also its sign. Moreover, it is argued that an average fiscal multiplier is of very little use to describe the effect of exogenous shifts in fiscal policy on output due to intrinsic heterogeneities.

\subsubsection{Labor market}

GVAR model developed by Hiebert and Vansteenkiste (2010) is used to analyze spillovers in the labor market in the US. Using data on 12 manufacturing industries over the period 1977-2003, Hiebert and Vansteenkiste (2010) analyze responses of a standard set of labor-market related variables (employment, real compensation, productivity and capital stock) to exogenous factors (such as a sector-specific measure of trade openness or a common technology shock), along with industry spillovers using specific measures of manufacturing-wide variables for each sector. Their findings indicate that increased trade openness negatively affects real compensation, has negligible employment effects and leads to higher labor productivity. The impacts of technology shocks are found to affect significantly and positively both real compensation and employment. 


\subsubsection{Role of credit}

The role of credit in the international business cycles is investigated using a GVAR approach in Eickmeier and Ng (2011), Xu (2012) and Konstantakis and Michaelides (2014). The first paper focuses on the transmission of credit supply shocks in the US, the euro area and Japan. Using sign restrictions on the short-run impulse responses to financial shocks that have the effect of reducing credit supply to the private sector, Eickmeier and Ng (2011) find that negative US credit supply shocks have stronger negative effects on domestic and foreign GDP, compared to credit supply shocks from the euro area and Japan. Domestic and foreign credit and equity markets respond to the credit supply shocks as well, and exchange rate responses are consistent with a flight to quality to the US dollar. Xu (2012) also investigates the effects of the US credit shocks and the importance of credit in explaining business cycle fluctuations. Her findings reveal the importance of bank credit in explaining output growth, changes in inflation and long term interest rates in countries with developed banking sector. Using GIRFs she finds strong evidence of the spillover of US credit shocks to the UK, the Euro area, Japan and other industrialized economies. Konstantakis and Michaelides (2014) use the GVAR approach to model output and debt fluctuations in the US and the EU15 economies. They analyzes the transmission of shocks to debt and GDP using GIRFs and find that EU15 economy is more vulnerable to foreign shocks as compared to the US. Moreover, the effects of a shock to the US debt has significant and persistent impact on the EU15 and US economies, whereas a shock to EU15 debt does not have statistically significant impact on the US economy.

\subsection{Sectoral and other applications}

The GVAR approach does not necessarily need to have a country dimension and other cross-section units could be considered. Holly and Petrella (2012) adopt the GVAR approach to model highly disaggregated manufacturing sectors. They uncover that factor demand linkages can be important for the transmission of both sectoral and aggregate shocks.

Vansteenkiste (2007) models regional housing market spillovers in the US. Using state-level data

on 31 largest US states she uncovers strong interregional linkages for both real house prices and real income per capita. Vansteenkiste (2007) also considers the effects of real interest rates shocks 
on house prices and finds that an increase of 100 basis points in the real 10-year government bond yield results in a relatively small long run fall in house prices of between 0.5 and $2.5 \%$.

Holly, Hashem Pesaran, and Yamagata (2011) investigate adjustment to shocks in a system of UK regional house prices, treating London as a dominant region and linking UK house prices also to the international developments via New York house price changes. They show that shocks to house prices in the London region impact other UK regions with a delay, and these lagged effects then echo back to London activity as the dominant region. Moreover, New York house prices have a direct effect on London house prices.

Chudik and Pesaran (2014) use highly disaggregated consumer price category data for Germany, France and Italy to investigate inflation persistence. They allow for neighborhood effects in their disaggregate GVAR model of consumer price categories. The objective of their analysis is to investigate the persistence of aggregate inflation. In particular, they investigate how the dynamic heterogeneity and the unobserved common factor persistence interact in their impact on consumer price inflation. Their findings suggests that the interaction of the persistence in common factors and the parameter heterogeneity are the key to understanding the slow response of the aggregate inflation to macro shocks.

\section{Concluding remarks}

Although the GVAR approach was originally developed for the purpose of credit risk modelling by Pesaran et al. (2004), it soon became clear that there are numerous possibilities for the application of this approach. Indeed, already there are numerous empirical applications of the GVAR approach developed over the last decade. Moreover, new theoretical insights are provided on the conditions that justify the individual building blocks of the GVAR model in large $N$ large $T$ setting where all variables are endogenously determined. Despite these developments, there are still areas that could greatly benefit from future research.

First, a deeper econometric understanding of the GVAR approach as $N, T \stackrel{j}{\rightarrow} \infty$ would be helpful. This includes several different areas, such as a better understanding of cross-country cointegration in high-dimensional VARs when $N$ is large, a more detailed analysis of the consequences of aggregation implicit in the data-shrinkage applied to observations for the rest-of-the-world economies, 
or linking the GVAR approach to the spatial literature.

The second important area is the integration of the GVAR the DSGE approaches to macroeconometric modelling. Since the GVAR approach provides a coherent reduced form VAR representation of the global economy, and solution of DSGE model is a VAR model, it will be useful to bring the two approaches together. A first step in this direction is provided by Dées, Pesaran, Smith, and Smith (2014), who consider a number of issues, including measurement of steady-states, the specification of short-run country-specific models and the identification and estimation of the model subject to the theoretical constraints required for a determinate rational expectation model. Full integration of the GVAR and the DSGE approaches would require development of $N$-country open economy DSGE models capable of modelling long-run as well as short-run business cycle movements. 


\section{References}

Alessandri, P., P. Gai, S. Kapadia, N. Mora, and C. Puhr (2009). Towards a framework for quantifying systemic stability. International Journal of Central Banking 5(3), 47-81.

Anderton, R., A. Galesi, M. Lombardi, and F. di Mauro (2010). Key elements of global inflation. In R. Fry, C. Jones, and C. Kent (Eds.), Inflation in an Era of Relative Price Shocks, RBA Annual Conference Volume. Reserve Bank of Australia.

Andrews, D. W. K. and W. Ploberger (1994). Optimal tests when a nuisance parameter is present only under the alternative. Econometrica 62(6), 1383-1414.

Bai, J. and S. Ng (2007). Determining the number of primitive shocks in factor models. Journal of Business and Economic Statistics 25, 52-60.

Bailey, N., M. H. Pesaran, and L. V. Smith (2014). A multiple testing approach to the regularisation of large sample correlation matrices. mimeo, 12 April 2014.

Banbura, M., D. Giannone, and L. Reichlin (2010). Large Bayesian vector auto regressions. Journal of Applied Econometrics 25, 71-92.

Berk, K. N. (1974). Consistent autoregressive spectral estimates. The Annals of Statistics 2, 489-502.

Bernanke, B. (1986). Alternative explanations of the money-income correlation. Carnegie-Rochester Conference Series on Public Policy 25, 49-99.

Bernanke, B. S., J. Bovian, and P. Eliasz (2005). Measuring the effects of monetary policy: A factoraugmented vector autoregressive (FAVAR) approach. Quarterly Journal of Economics 120, 387-422.

Bettendorf, T. (2012). Investigating global imbalances: Empirical evidence from a GVAR approach. Studies in Economics 1217, Department of Economics, University of Kent.

Bickel, P. J. and E. Levina (2008). Covariance regularization by thresholding. The Annals of Statistics 36, $2577-2604$.

Binder, M. and M. Gross (2013). Regime-switching global vector autoregressive models. Working Paper Series 1569, European Central Bank.

Blanchard, O. J. and D. Quah (1989). The dynamic effects of aggregate demand and supply disturbances. The American Economic Review 79, 655-673.

Blanchard, O. J. and M. W. Watson (1986). Are business cycles all alike? In R. J. Gordon (Ed.), The American business cycle: Continuity and change, pp. 123-180. University of Chicago Press.

Bussière, M., A. Chudik, and A. Mehl (2011). How have global shocks impacted the real effective exchange rates of individual euro area countries since the euro's creation? The BE Journal of Macroeconomics 13, 1-48.

Bussière, M., A. Chudik, and G. Sestieri (2012). Modelling global trade flows: results from a gvar model. Globalization and Monetary Policy Institute Working Paper 119, Federal Reserve Bank of Dallas.

Canova, F. and G. de Nicoló (2002). Monetary disturbances matter for business fluctuations in the G-7. Journal of Monetary Economics 49, 1131-1159.

Canova, F. and J. Pina (1999). Monetary policy misspecification in VAR models. Centre for Economic Policy Research, Discussion Paper No 2333.

Carriero, A., G. Kapetanios, and M. Marcellino (2009). Forecasting exchange rates with a large Bayesian VAR. International Journal of Forecasting 25, 400-417. 
Cashin, P., K. Mohaddes, M. Raissi, and M. Raissi (2014). The differential effects of oil demand and supply shocks on the global economy. forthcoming in Energy Economics. doi: 10.1016/j.eneco.2014.03.014.

Castrén, O., S. Dées, and F. Zaher (2010). Stress-testing euro area corporate default probabilities using a global macroeconomic model. Journal of Financial Stability 6(2), 64-78.

Cesa-Bianchi, A., M. H. Pesaran, and A. Rebucci (2014). Uncertainty and economic activity: A global perspective. Mimeo, 20 February 2014.

Cesa-Bianchi, A., M. H. Pesaran, A. Rebucci, and T. Xu (2012). China's emergence in the world economy and business cycles in Latin America. Journal of LACEA Economia.

Cheung, Y. and K. S. Lai (1993). Finite-sample sizes of Johansen's likelihood ratio tests for cointegration. Oxford Bulletin of Economics and Statistics 55, 315-328.

Chudik, A. and M. Fidora (2012). How the global perspective can help us to identify structural shocks. Federal Reserve Bank of Dallas Staff Paper No. 19.

Chudik, A. and M. Fratzscher (2011). Identifying the global transmission of the 2007-2009 financial crisis in a GVAR model. European Economic Review 55(3), 325-339.

Chudik, A., V. Grossman, and M. H. Pesaran (2014). Nowcasting and forecasting global growth with purchasing managers indices. Mimeo, January 2014.

Chudik, A. and M. H. Pesaran (2011). Infinite dimensional VARs and factor models. Journal of Econometrics 163, 4-22.

Chudik, A. and M. H. Pesaran (2013a). Common correlated effects estimation of heterogeneous dynamic panel data models with weakly exogenous regressors. CESifo Working Paper No. 4232.

Chudik, A. and M. H. Pesaran (2013b). Econometric analysis of high dimensional VARs featuring a dominant unit. Econometric Reviews 32, 592-649.

Chudik, A. and M. H. Pesaran (2014). Aggregation in large dynamic panels. forthcoming in Journal of Econometrics.

Chudik, A. and V. Smith (2013). The GVAR approach and the dominance of the U.S. economy. Federal Reserve Bank of Dallas, Globalization and Monetary Policy Institute Working Paper No. 136.

Clarida, R. and J. Gali (1994). Sources of real exchange rate fluctuations: How important are nominal shocks? Carnegie-Rochester Series on Public Policy 41, 1-56.

De Mol, C., D. Giannone, and L. Reichlin (2008). Forecasting using a large number of predictors: Is Bayesian shrinkage a valid alternative to principal components? Journal of Econometrics 146, 318328.

de Waal, A. and R. van Eyden (2013a). Forecasting key South African variables with a global VAR model. Working Papers 201346, University of Pretoria, Department of Economics.

de Waal, A. and R. van Eyden (2013b). The impact of economic shocks in the rest of the world on South Africa: Evidence from a global VAR. Working Papers 201328, University of Pretoria, Department of Economics.

de Wet, A. H., R. van Eyden, and R. Gupta (2009). Linking global economic dynamics to a South Africanspecific credit risk correlation model. Economic Modelling 26(5), 1000-1011.

di Mauro, F. and M. H. Pesaran (2013). The GVAR Handbook: Structure and Applications of a Macro Model of the Global Economy for Policy Analysis. Oxford University Press. 
Diebold, F. X. and R. Mariano (1995). Comparing predictive accuracy. Journal of Business and Economic Statistics 13, 253-263.

Dovern, J. and B. van Roye (2013). International transmission of financial stress: evidence from a GVAR. Kiel Working Papers 1844, Kiel Institute for the World Economy.

Dreger, C. and J. Wolters (2011). Liquidity and asset prices: How strong are the linkages? Review of Economics \& Finance 1, 43-52.

Dreger, C. and Y. Zhang (2013). Does the economic integration of China affect growth and inflation in industrial countries? FIW Working Paper series 116, FIW.

Dubois, E., J. Hericourt, and V. Mignon (2009). What if the euro had never been launched? A counterfactual analysis of the macroeconomic impact of euro membership. Economics Bulletin 29(3), 2241-2255.

Dées, S., F. di Mauro, M. H. Pesaran, and L. V. Smith (2007). Exploring the international linkages of the Euro Area: A global VAR analysis. Journal of Applied Econometrics 22, 1-38.

Dées, S., S. Holly, M. H. Pesaran, and L. V. Smith (2007). Long run macroeconomic relations in the global economy. Economics - The Open-Access, Open-Assessment E-Journal 1(3), 1-20.

Dées, S., M. H. Pesaran, L. V. Smith, and R. P. Smith (2009). Identification of New Keynesian Phillips curves from a global perspective. Journal of Money, Credit and Banking 41(7), 1481-1502.

Dées, S., M. H. Pesaran, L. V. Smith, and R. P. Smith (2014). Constructing multi-country rational expectations models. forthcoming in Oxford Bulletin of Economics and Statistics.

Dées, S. and A. Saint-Guilhem (2011). The role of the United States in the global economy and its evolution over time. Empirical Economics 41(3), 573-591.

Eickmeier, S. and T. Ng (2011). How do credit supply shocks propagate internationally? A GVAR approach. Discussion Paper Series 1: Economic Studies 2011-27, Deutsche Bundesbank, Research Centre.

Eklund, J. and G. Kapetanios (2008). A review of forecasting techniques for large data sets. National Institute Economic Review 203(1), 109-115.

Ericsson, N. and E. Reisman (2012). Evaluating a global vector autoregression for forecasting. International Advances in Economic Research 18(3), 247-258.

Fan, J., Y. Fan, and J. Lv (2008). High dimensional covariance matrix estimation using a factor model. Journal of Econometrics 147(1), 186-197.

Faust, J. (1998). The robustness of identified VAR conclusions about money. Carnegie-Rochester Conference Series in Public Policy 49(1), 207-244.

Favero, C., F. Giavazzi, and J. Perego (2011). Country heterogeneity and the international evidence on the effects of fiscal policy. IMF Economic Review 59(4), 652-682.

Feldkircher, M. (2013). A global macro model for Emerging Europe. Working Papers 185, Oesterreichische Nationalbank (Austrian Central Bank).

Feldkircher, M., F. Huber, and J. C. Cuaresma (2014). Forecasting with bayesian global vector autoregressive models: A comparison of priors. Oesterreichische Nationalbank (Austrian Central Bank) Working Paper No. 189.

Feldkircher, M. and I. Korhonen (2012). The rise of China and its implications for emerging markets - evidence from a GVAR model. BOFIT Discussion Papers 20/2012, Bank of Finland, Institute for Economies in Transition. 
Forni, M., M. Hallin, M. Lippi, and L. Reichlin (2000). The generalized dynamic factor model: Identification and estimation. Review of Economics and Statistic 82, 540-554.

Forni, M., M. Hallin, M. Lippi, and L. Reichlin (2004). The generalized dynamic factor model: Consistency and rates. Journal of Econometrics 119, 231-235.

Forni, M. and M. Lippi (1997). Aggregation and the Microfoundations of Dynamic Macroeconomics. Oxford University Press, Oxford.

Forni, M. and M. Lippi (2001). The generalized factor model: Representation theory. Econometric Theory $17,1113-1141$.

Friedman, J., T. Hastie, and R. Tibshirani (2008). Sparse inverse covariance estimation with the graphical lasso. Biostatistics 9(3), 432-441.

Galesi, A. and M. J. Lombardi (2009). External shocks and international inflation linkages: a global VAR analysis. Working Paper Series 1062, European Central Bank.

Garratt, T., K. Lee, M. H. Pesaran, and Y. Shin (2006). Global and National Macroeconometric Modelling: A Long Run Structural Approach. Oxford: Oxford University Press.

Geweke, J. (1977). The dynamic factor analysis of economic time series. In D. Aigner and A. Goldberger (Eds.), Latent variables in socio-economic models. Amsterdam: North-Holland.

Giacomini, R. and H. White (2006). Tests of conditional predictive ability. Econometrica 74, 1545-1578.

Giannone, D., L. Reichlin, and L. Sala (2005). Monetary policy in real time. In M. Gertler and K. Rogoff (Eds.), NBER Macroeconomics Annual 2004, Volume 19, pp. 161-200. MIT Press.

Granger, C. W. and Y. Jeon (2007). Evaluation of global models. Economic Modelling 24(6), 980-989.

Granger, C. W. J. (1987). Implications of aggregation with common factors. Econometric Theory 3, 208222.

Gray, D. F., M. Gross, J. Paredes, and M. Sydow (2013). Modeling banking, sovereign, and macro risk in a CCA Global VAR. IMF Working Papers 13/218, International Monetary Fund.

Greenwood-Nimmo, M., V. H. Nguyen, and Y. Shin (2012a). International linkages of the Korean economy: The global vector error-correcting macroeconometric modelling approach. Melbourne Institute Working Paper Series wp2012n18, Melbourne Institute of Applied Economic and Social Research, The University of Melbourne.

Greenwood-Nimmo, M., V. H. Nguyen, and Y. Shin (2012b). Probabilistic forecasting of output, growth, inflation and the balance of trade in a GVAR framework. Journal of Applied Econometrics 27, 554-573.

Groen, J. J. J. and G. Kapetanios (2008). Revisiting useful approaches to data-rich macroeconomic forecasting. Federal Reserve Bank of New York, Staff Report No. 327, revised September 2009.

Gross, M. (2013). Estimating GVAR weight matrices. Working Paper Series 1523, European Central Bank.

Gross, M. and C. Kok (2013). Measuring contagion potential among sovereigns and banks using a mixedcross-section GVAR. Working Paper Series 1570, European Central Bank.

Gutierrez, L. and F. Piras (2013). A global wheat market model (GLOWMM) for the analysis of wheat export prices. 2013 Second Congress, June 6-7, 2013, Parma, Italy 149760, Italian Association of Agricultural and Applied Economics (AIEAA).

Harbo, I., S. Johansen, B. Nielsen, and A. Rahbek (1998). Asymptotic inference on cointegrating rank in partial systems. Journal of Business and Economic Statistics 16, 388-399. 
Hastie, T., R. Tibshirani, and J. Friedman (2009). The Elements of Statistical Learning (2nd ed.). Springer.

Hiebert, P. and I. Vansteenkiste (2009). Do house price developments spill over across euro area countries? Evidence from a Global VAR. Working Paper Series 1026, European Central Bank.

Hiebert, P. and I. Vansteenkiste (2010). International trade, technological shocks and spillovers in the labour market: a GVAR analysis of the US manufacturing sector. Applied Economics 42(24), 30453066.

Holly, S., M. Hashem Pesaran, and T. Yamagata (2011). The spatial and temporal diffusion of house prices in the UK. Journal of Urban Economics 69(1), 2-23.

Holly, S. and I. Petrella (2012). Factor demand linkages, technology shocks, and the business cycle. The Review of Economics and Statistics 94(4), 948-963.

Inoue, A. and L. Kilian (2013). Inference on impulse response functions in structural VAR models. Journal of Econometrics 177(1), 1-13.

Jannsen, N. (2010). National and international business cycle effects of housing crises. Applied Economics Quarterly (formerly: Konjunkturpolitik) 56(2), 175-206.

Konstantakis, K. N. and P. G. Michaelides (2014). Transmission of the debt crisis: From EU15 to USA or vice versa? A GVAR approach. forthcoming in Journal of Economics and Business, http://dx.doi.org/10.1016/j.jeconbus.2014.04.001.

Koop, G., M. H. Pesaran, and S. M. Potter (1996). Impulse response analysis in nonlinear multivariate models. Journal of Econometrics 74, 119-147.

Ledoit, O. and M. Wolf (2004). A well-conditioned estimator for large-dimensional covariance matrices. Journal of Multivariate Analysis 88, 365-411.

Mountford, A. and H. Uhlig (2009). What are the effects of fiscal policy shocks? Journal of Applied Econometrics 24, 960-992.

Nyblom, J. (1989). Testing for the constancy of parameters over time. Journal of the American Statistical Association 84, 223-230.

Pesaran, M. H. (2003). Aggregation of linear dynamic models: An application to life-cycle consumption models under habit formation. Economic Modelling 20, 383-415.

Pesaran, M. H. (2006). Estimation and inference in large heterogeneous panels with multifactor error structure. Econometrica 74, 967-1012.

Pesaran, M. H., T. Schuermann, and L. V. Smith (2009a). Forecasting economic and financial variables with global VARs. International Journal of Forecasting 25(4), 642-675.

Pesaran, M. H., T. Schuermann, and L. V. Smith (2009b). Rejoinder to comments on forecasting economic and financial variables with global VARs. International Journal of Forecasting 25(4), 703-715.

Pesaran, M. H., T. Schuermann, and B.-J. Treutler (2007). Global business cycles and credit risk. In The Risks of Financial Institutions, NBER Chapters, pp. 419-474. National Bureau of Economic Research, Inc.

Pesaran, M. H., T. Schuermann, B.-J. Treutler, and S. M. Weiner (2006). Macroeconomic dynamics and credit risk: A global perspective. Journal of Money, Credit and Banking 38(5), 1211-1261.

Pesaran, M. H., T. Schuermann, and S. M. Weiner (2004). Modelling regional interdependencies using a global error-correcting macroeconometric model. Journal of Business and Economics Statistics 22, 129-162. 
Pesaran, M. H. and Y. Shin (1996). Cointegration and speed of convergence to equilibrium. Journal of Econometrics 71(1-2), 117-143.

Pesaran, M. H. and Y. Shin (1998). Generalised impulse response analysis in linear multivariate models. Economics Letters 58, 17-29.

Pesaran, M. H., Y. Shin, and R. J. Smith (2000). Structural analysis of vector error correction models with exogenous I(1) variables. Journal of Econometrics 97, 293-343.

Pesaran, M. H., L. V. Smith, and R. P. Smith (2007). What if the UK or Sweden had joined the euro in 1999? An empirical evaluation using a Global VAR. International Journal of Finance ES Economics 12(1), 55-87.

Pesaran, M. H. and R. Smith (2006). Macroeconometric modelling with a global perspective. Manchester School 74, 24-49.

Pesaran, M. H. and R. P. Smith (1998). Structural analysis of cointegrating VARs. Journal of Economic Surveys 12, 471-505.

Ploberger, W. and W. Krämer (1992). The CUSUM test with OLS residuals. Econometrica 60(2), 271-286.

Quandt, R. E. (1960). Tests of the hypothesis that a linear regression system obeys two separate regime. Journal of the American Statistical Association 55, 324-330.

Said, E. and D. A. Dickey (1984). Testing for unit roots in autoregressive-moving average models of unknown order. Biometrika 71, 599-607.

Sargent, T. J. and C. A. Sims (1977). Business cycle modeling without pretending to have too much apriori economic theory. In C. Sims (Ed.), New methods in business cycle research. Minneapolis: Federal Reserve Bank of Minneapolis.

Schanne, N. (2011). Forecasting regional labour markets with GVAR models and indicators. ERSA conference papers ersa10p1044, European Regional Science Association.

Sims, C. (1980). Macroeconomics and reality. Econometrica 48, 1-48.

Sims, C. (1986). Are forecasting models usable for policy analysis? Quarterly Review, Federal Reserve Bank of Minneapolis 10, 105-120.

Smith, L. and A. Galesi (2014). Gvar toolbox 2.0. Toolbox is available at: https://sites.google.com/site/gvarmodelling/gvar-toolbox/download.

Smith, L. V. and T. Yamagata (2011). Firm level return-volatility analysis using dynamic panels. Journal of Empirical Finance 18(5), 847-867.

Stock, J. H. and M. W. Watson (1999). Forecasting inflation. Journal of Monetary Economics 44, 293-335.

Stock, J. H. and M. W. Watson (2002). Macroeconomic forecasting using diffusion indexes. Journal of Business and Economic Statistics 20, 147-162.

Stock, J. H. and M. W. Watson (2005). Implications of dynamic factor models for VAR analysis. NBER Working Paper No. 11467.

Sun, Y., F. F. Heinz, and G. Ho (2013). Cross-country linkages in Europe: A Global VAR analysis. IMF Working Papers 13/194, International Monetary Fund.

Tibshirani, R. (1996). Regression shrinkage and selection via the Lasso. Journal of the Royal Statistical Society Series B 58, 267-288.

Uhlig, H. (2005). What are the effects of monetary policy on output? results from an agnostic identification procedure. Journal of Monetary Economics 52, 381-419. 
Vansteenkiste, I. (2007). Regional housing market spillovers in the US: lessons from regional divergences in a common monetary policy setting. Working Paper Series 0708, European Central Bank.

Wold, H. (1982). Soft modeling: The basic design and some extensions. In K. G. Joreskog and H. Wold (Eds.), Systems under indirect observation: Causality, structure, prediction: Vol. 2, pp. 589-591. Amsterdam: North-Holland.

$\mathrm{Xu}, \mathrm{T}$. (2012, January). The role of credit in international business cycles. Cambridge Working Papers in Economics 1202, Faculty of Economics, University of Cambridge.

Zaffaroni, P. (2004). Contemporaneous aggregation of linear dynamic models in large economies. Journal of Econometrics 120, 75-102. 